This item was submitted to Loughborough's Research Repository by the author.

Items in Figshare are protected by copyright, with all rights reserved, unless otherwise indicated.

\title{
Biodiversity valuation and the discount rate problem
}

PLEASE CITE THE PUBLISHED VERSION

http://dx.doi.org/10.1108/AAAJ-02-2013-1226

\section{PUBLISHER}

(c) Emerald Group Publishing Limited

VERSION

AM (Accepted Manuscript)

LICENCE

CC BY-NC-ND 4.0

REPOSITORY RECORD

Freeman, Mark, and Ben Groom. 2019. "Biodiversity Valuation and the Discount Rate Problem". figshare. https://hdl.handle.net/2134/14959. 
This item was submitted to Loughborough's Institutional Repository (https://dspace.lboro.ac.uk/) by the author and is made available under the following Creative Commons Licence conditions.

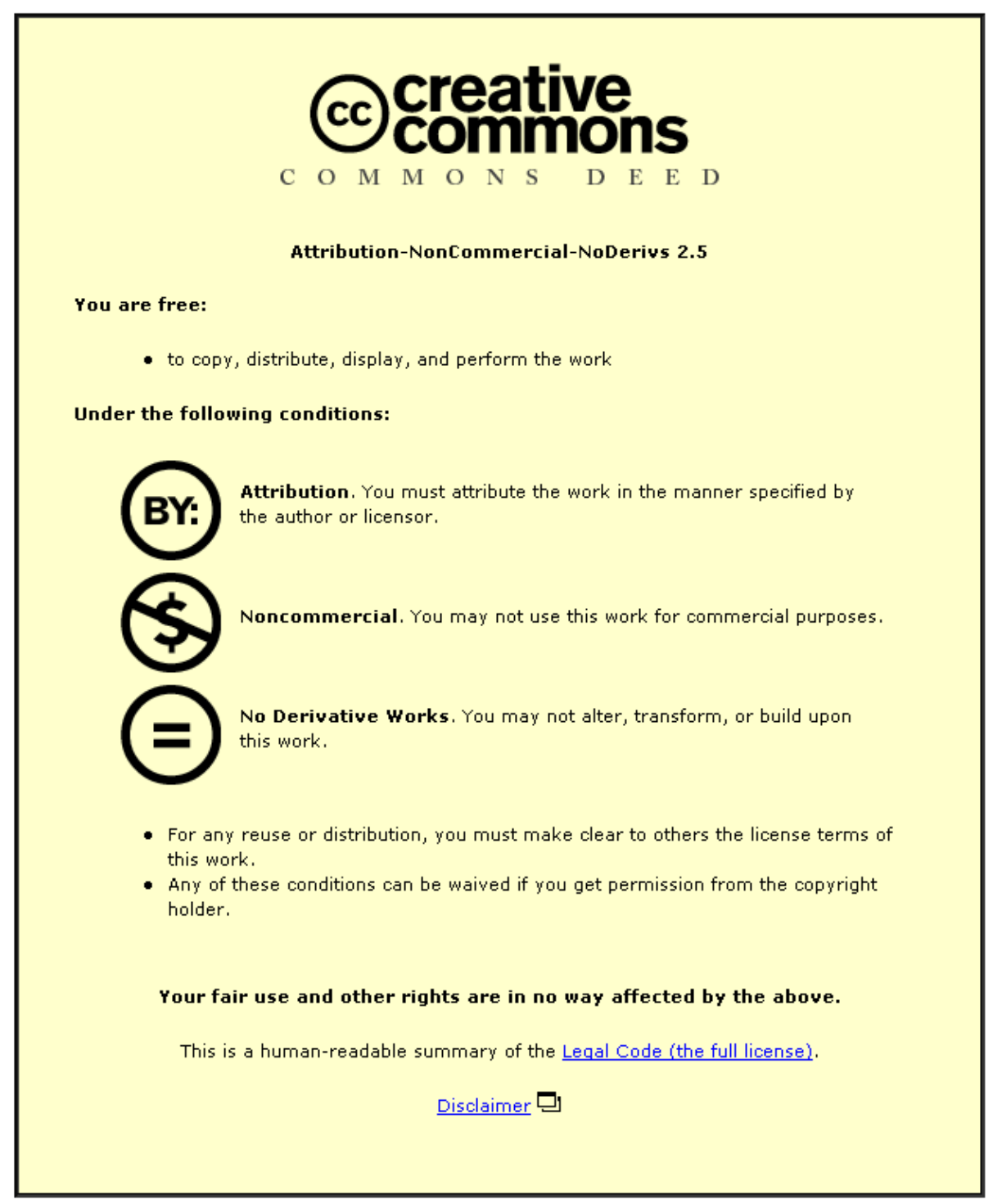

For the full text of this licence, please go to: http://creativecommons.org/licenses/by-nc-nd/2.5/ 


\section{Biodiversity valuation and the discount rate problem}

\section{Structured Abstract}

Purpose: To demonstrate that the application of standard environmental accounting practices for estimating long-term discount rates is likely to lead to the rejection of biodiversity-sensitive projects that are in the greater societal good.

Design/methodology/approach: We combine estimates of marginal ecosystem damages from two forestry case studies, one local, one global, with ten different term structures of discount rates taken from both the academic literature and policy choices to calculate present values.

Findings: Standard environmental accounting approaches for estimating the long-term discount rate result in the under-valuation of projects that are sensitive to biodiversity conservation.

Research limitations/implications: This paper is set within a Full Cost Accounting (FCA) framework, and therefore has the limitations that generally follow from taking this approach to biodiversity problems. Recommended extensions include looking at broader ranges of biodiversity costs and benefits.

Practical/social implications: Unless environmental accountants engage with environmental economists over the issue of intergenerational discount rates, then it is likely that socially responsible managers will reject projects that are in the greater societal good.

Originality/value: (i) To introduce both normative discount rates and declining discount rates to estimates of shadow environmental provisions within FCA and to contrast these with current environmental accounting practices, (ii) To provide two detailed case studies that demonstrate the extent to which biodiversity-sensitive investment choices are likely to be undervalued by managers who follow current accounting recommendations concerning the appropriate choice of discount rate.

Keywords: Biodiversity Accounting, Ecosystem Services, Valuation, Declining Discount Rates, Gamma Discounting, Normative, Positive.

Article Classification: Research Paper. 


\section{Biodiversity valuation and the discount rate problem}

\section{Introduction}

The objective of Full Cost Accounting (FCA) is to meet the 'triple bottom line' of measuring in monetary terms the full economic, environmental and social costs of a corporation's activities (e.g., Elkington, 2003). FCA addresses the fact that the activities of many corporations have environmental impacts (for example, air pollution or impacts on habitat and biodiversity) which are external to usual accounting procedures and therefore ignored in decision-making. Furthermore, environmental costs and benefits typically extend beyond the usual planning time horizon for corporations. For instance, losses of biodiversity arising from, say, deforestation are often irreversible. Hence the costs of biodiversity loss, and particularly extinction, last forever. Yet the difficulties do not end there. Even if environmental costs and benefits are included within accounting procedures, and the corporate planning horizons extended over centuries, there remains the issue of how to value from today's perspective the costs of biodiversity loss in the far distant future. Put in terms of cost-benefit analysis, the question is: what discount rate should be deployed to evaluate investment decisions with implications which extend into the distant future and affect future generations?

In this paper we extend the literature by considering in detail the discount rate that should be used to calculate 'shadow environmental provisions' of biodiversity-sensitive projects. These reflect the "net present value of the expected external environmental costs as calculated for the environmental accounts ... The shadow provision is an indication of how much the company knows that it will draw on external human, social and natural capitals to be able to perform its value creation in the future" (Richardson and Bent, 2003, pp. 31-32).

The shadow biodiversity provision of an organisation, as might be reflected on an environmental balance sheet, will be highly sensitive to the choice of discount rate. Conservation of biodiversity and ecosystem services is typified by flows of benefits which persist over time horizons of hundreds of years, possibly millennia. For this reason, the relative importance of such benefits in any evaluation of investments in conservation, or equivalently, the costs of biodiversity loss associated with alternative investments, is fundamentally determined by the weight placed on cash flows in the future. It is well known that at such horizons the calculated present value is highly sensitive to the cost of capital. For example, the present value of a monetised biodiversity benefit in 150 years is $320 \%$ higher when calculated at $4 \%$ than at $5 \%$. It 
is also important that managers are confident of their ground when choosing a discount rate because, as noted by Boyce (2000), this is an area that would be open for challenge by any given pressure group contesting an ecologically sensitive investment decision.

We make two key contributions. The first lies within a general FCA framework that is relevant beyond accounting for biodiversity alone. Standard accounting guidelines for long-term discounting rely on observable market rates of interest; a practice commonly referred to as 'positive' or 'descriptive' discounting. We argue that these accounting-based recommendations will lead socially responsible managers to reject environmental- and ecosystems-sensitive projects that are in the greater societal good. There are two reasons for this. First, there are strong reasons for taking a 'normative / prescriptive' approach to long-term decision-making that bases the discount rate on ethical considerations of intergenerational justice. Second, there has been increasing recognition that decision-makers should use declining discount rates (DDRs) when looking at very long-term cash flows both within positive and normative discounting paradigms. Such declining schedules are now incorporated into Government-body recommendations in the US, the UK and France. Both these effects significantly increase the calculated present value of future environmental and biodiversity benefits when compared against those that result from the cost of capital recommendations arising from existing accounting practice.

Our second contribution is to quantify the potential magnitude of undervaluation of shadow biodiversity provisions when managers use market interest rates to inform their long-term discount rate. ${ }^{[1]}$ We undertake two case studies, one local and the other global with both being based on the biodiversity benefits of sustainable forestry practice. The local study that we present extends the work of Hepburn and Koundouri (2007) by comparing long- and shortrotation forestry practices. The global case study employs the Global Unified Meta-model of the Biosphere (GUMBO). This provides a detailed array of global ecosystem values for forest cover and therefore overcomes the failure to evaluate the full range of consequences that has been highlighted as a typical problem with economic analyses of biodiversity in the past (TEEB, 2011). In addition, since ecosystem values are an integral part of the GUMBO model, changes in relative prices associated with ecosystem changes are reflected in the benefit stream evaluated. This overcomes recent criticisms of standard discounting approaches, which frequently ignore such issues (Sterner and Persson, 2008). 
In each case, we discount the monetised benefits of biodiversity-sensitive forestry practices using ten different discount rate schedules that have been recommended either in the academic literature or by policy makers. We show that, for the local forestry example, using a fixed market interest rate of $4 \%$ (all cash flows and discount rates in this paper are given in real terms), as might be suggested by current accounting practices, leads to a strong preference for short-term pine forestry planting in preference to more biodiversity-friendly broad-leaved species, such as oak. By contrast, a number of alternative cost of capital choices, including those recommended by the Stern Review, would lead socially responsible managers to plant oak in preference to pine. In the global example, compared to a fixed $4 \%$ discount rate, certain schedules increase the present value of ecosystem damages by between $50 \%$ and over $1000 \%$ due to the higher relative weight placed on damages that occur in the distant future.

The central conclusion of our paper is that managers who wish to fulfil their corporate social responsibility role should be cautious in using standard accounting recommendations concerning the choice of fixed market-based discount rates when calculating shadow environmental and biodiversity provisions within an FCA framework. Instead, we would recommend that they carefully consider the literature from environmental economics and the recommendations of social policy makers. ${ }^{[2]}$ A positive, but declining, schedule of discount rates, as recommended by Newell and Pizer (2003), and Groom et al. (2007), may best reflect the strong arguments for using lower discount rates for intergenerational projects while remaining within the accounting tradition of basing costs of capital on observable interest rates. If starting at a short-term real rate of $4 \%$, this would result in a recommendation of a real discount rate of $3.00 \%$ at 50 years, $2.25 \%$ at 100 years, $1.50 \%$ at 200 years and $1.15 \%$ at 300 years. As we show in our local example, this would provide a rigorous accounting-based justification for planting broad-leaved, biodiversity sensitive, forests in preference to pine.

The paper proceeds as follows. The following section briefly discusses FCA and other environmental accounting practices that are relevant to discounting in the context of biodiversity and ecosystem services with particular emphasis on the choice of cost of capital. Section 3 then considers the alternative normative framework for intergenerational discounting that is preferred by many environmental economists and that generally results in the choice of a discount rate than is lower than current market rates. Section 4 turns to declining discount rates, which provides further justification for using low costs of capital at long horizons. Section 5 describes the two case studies that we are considering. In Section 6 we illustrate the 
sensitivity of ecosystem values to the schedule of discount rates employed. Section 7 concludes by summarising the main findings and offering guidance.

\section{Economic accounting for biodiversity}

Except under very limited circumstances, current financial accounting standards do not require firms to explicitly recognise costs associated with biodiversity degradation that arise from their activities. The most relevant section of the International Accounting Standards is IAS 37 and the associated IFRIC 1, which underpin the accounting requirements for calculating the present value of future liabilities associated with decommissioning nuclear power sites. This is clearly a closely related area to biodiversity accounting as the cash flows are spread over very long time horizons and there are environmental consequences to the operation. However, this code only relates to items "that create a legal or constructive obligation and, therefore, results in an entity having no realistic alternative but to settle the obligation" [IAS 37.10]. Under the European Union Environmental Liabilities Directive (Dir. 2004/35/EC), there is a 'polluter pays' principle for protected species and habitats (Grabsch et al., 2012), but this is quite limited in terms of the actual biodiversity damage that an organisation might inflict. Grabsch et al. (2012) evidence the lack of detailed financial accounting for biodiversity that is undertaken in practice by large companies in the UK and Germany.

The emergence of stakeholder and stewardship approaches, as well as the advent of Corporate Social Responsibility (CSR) has emphasised the importance of the wider social and environmental sphere within which business currently operates (Brennan and Solomon, 2008). Given the limitations of existing financial standards, Jones (2010) presents a new theoretical framework for environmental accounting and reporting in which he argues that it is essential that such a framework should recognise such corporate stewardship responsibilities. This is consistent with his earlier observation that "the maintenance of natural inventories is one possible way in which they can discharge their social obligations" (Jones, 2003, p.781). Full Cost Accounting, for which Davies (2009), Houdet et al. (2009) and Jones (2010) amongst others provide recent comprehensive reviews, lies within this broader stewardship framework. It extends existing financial standards to include monetised values of external costs and benefits to the broader environment and society. Perhaps the best-known implementation of this is the Sustainability Assessment Model developed by BP (see, for example, Bebbington and Frame, undated). 
Within an FCA framework, Richardson and Bent (2003) emphasise the need to distinguish between stock and flow items. In this paper, we consider one particular balance sheet item; the 'shadow environmental provisions' of biodiversity-sensitive projects. This is calculated as the present value of the expected net future monetised biodiversity costs or benefits, $\pi_{t}$, that arise from a project with maturity $T$ when a discount rate $r$ is applied: $:^{[3]}$

$$
N P V=\pi_{0}+\frac{1}{(1+r)} \pi_{1}+\frac{1}{(1+r)^{2}} \pi_{2}+\ldots \ldots .+\frac{1}{(1+r)^{T}} \pi_{T}
$$

While, in principle, this is equivalent to accounting for other long-term corporate liabilities on a company's balance sheet, such as pension fund obligations or nuclear decommissioning costs, a number of specific difficulties arise in the case of FCA. Perhaps the most important of these is the difficulty in providing estimates of $\pi_{t}$. Some, for example, argue that biodiversity and environmental assets have an 'intrinsic' value beyond that which can be expressed through the anthropocentric lens of human utility: "I suggest that the aggregate value of a chunk of nature - its aesthetic beauty, cultural importance and evolutionary significance - is infinite, and thus defies incorporation into any ecosystem service programme that aims to save nature by approximating its monetary value" (McCauley, 2006, p.27). Similarly, although global ecosystem benefits such as climate regulation, water purification and nutrient recycling have been estimated to be worth several multiples of global GDP, even these estimates have been described as 'a significant underestimate of infinity' (Costanza et al., 1997; Toman 1998). While critiques of this intrinsic approach to environmentalism are also prevalent in the literature (e.g., Antheaume, 2007; Justus et al., 2009), many continue to subscribe to this view.

Even for those who do not, the difficulties of how to estimate $\pi_{t}$ are formidable. First, given the complex and dynamic interactions between business and the biosphere it is difficult to know 'where to draw the boundaries' when determining marginal effects. Even once this is decided, methodological choices on whether to use hedonistic or contingent valuation techniques to value biodiversity (for example, Meinard and Grill, 2011), and the more detailed specific choice of methods, must then be made. As Bebbington and Frame (undated, p.2) observe "The main approaches to monetisation ... may yield significantly different measures of externalities". Even once these hurdles have been crossed, a specific monetary value must still be placed on each aspect of biodiversity that is included within the boundaries of analysis, which is a highly 
challenging and controversial task. As a consequence, Houdet et al. (2009) point to a lack of independent verification mechanisms and consensual approaches so that users of financial statements may have a consistent representation of different organisations' activities within the biosphere.

While these, and related, issues concerning the monetisation of costs and benefits of biodiversity disruption have been widely discussed within the FCA literature, they are not our focus here. Instead, we concentrate on the other variable that influences shadow biodiversity provisions, that is; $r$. While Richardson and Bent (2003, p.32) state that "choosing an appropriate discount rate would be a challenge", to our knowledge, there has been little previous detailed consideration of this point. This contrasts with the extensive literature within environmental economics on long-term social discount rates, which we will review in the next two sections.

In the absence of any specific recommendations for the choice of $r$ within the FCA literature and given the clear similarities between general intergenerational environmental issues and nuclear decommissioning, a strong argument could be made that accounting standard IAS 37 / IFRIC 1 is the one most suited for the purpose of valuing the costs and benefits that arise from biodiversity initiatives. Provisions would then be based on "the amount that an entity would rationally pay to settle the obligation at the balance sheet date or to transfer it to a third party" [IAS 37.36] at "the current market-based discount rate" [IFRIC 1].

This is largely in line with US GAAP policy on nuclear decommissioning. As Taylor (2008, p.18) notes "the accounting treatment of nuclear liabilities has converged somewhat over the last decade between US, UK and International principles. Decommissioning liabilities must be recognised in full at their present value, using an appropriate market based discount rate". In terms of what the market interest rate should be, Taylor (2008) argues that the decision should be consistent with that used for discounting the liabilities of defined benefit pension plans. Under IAS 19, "the rate used to discount estimated cash flows should be determined by reference to market yields at the balance sheet date on high quality corporate bonds" [IAS 19.78] which is generally interpreted to refer to those that are AA-rated. ${ }^{[4]}$

The theoretical justification for this positivist approach is well-known: "Any action that would divert some of this productive capital to finance a safe investment project whose return is 
smaller than the interest rate would destroy wealth. If asked, future generations would reject this action. This arbitrage argument provides a strong argument for using the interest rate as the rate to discount risk free investment projects" (Gollier, 2012, p.3). Despite this, Beckerman and Hepburn (2007) remind us of Amartya Sen's (1982) reservations about market interest rates. Future generations are absent from current markets which only reflect the preferences of the present generation, who may not consider future generations at all. In this sense financial markets fail and discounting using market rates will lead to inefficient investment decisions, to which future generations would object if they could. Sen (1982) argues that current generations and their governments have a 'super-responsibility' to reflect these preferences. These unavoidable ethical considerations tie in directly with the issue of sustainable economic development, which has also been the focus of recent developments in corporate finance and corporate governance (e.g., Guthrie and Parker, 2011). Sen (1982) also argues that individuals act with different 'hats' on: we behave in different ways depending on the context and play different roles in the marketplace compared to when considering ethical or political questions. Members of the current generation may be more concerned about future generations when wearing their 'political hat' than is reflected in their decisions in the marketplace with their 'consumer hat' on. The former is more appropriate for questions of intergenerational equity. Beyond this, Beckerman and Hepburn (2007) argue that, even if markets were perfect, the aggregation of individual preferences embodied in market prices may not be appropriate for intergenerational decision-making. For instance, market prices reflect the current distribution of income, and people with higher incomes have disproportionate influence in the market place. For this reason, many believe that market prices may not necessarily form a sound basis for the essentially ethical decisions associated with intergenerational projects. In short, there are numerous reasons why, despite reflecting how current generations actually do trade-off costs and benefits over time, it may be a mistake for a socially responsible manager to use this observed rate for intergenerational analysis.

Because of these concerns, many economists prefer to use normative techniques when calculating present values of future environmental damage. The normative school asks the question 'how ought we to discount the future?', as opposed to the positive school that asks the question 'how do we discount the future?'. When considering intergenerational projects the distinction between these two approaches can be extremely important and, as we show in Sections 5 and 6, leads to large differences in valuation for biodiversity-sensitive projects at both the local and global levels. Our central argument is that, because FCA takes a 
stewardship view of the organisation, there are strong arguments for managers to favour either the ethical considerations contained within normative economics or a positivist approach that allows for declining discount rates. As we show below, both these approaches are likely to increase the estimated present value of future biodiversity costs and make it less likely that socially responsible managers will reject biodiversity-sensitive projects that are in the greater societal good.

\section{Normative approaches to discounting}

The economic accounting of biodiversity and environmental projects currently has very high policy relevance. In October 2011, the World Bank announced the launch of the Global Partnership for Ecosystems and Ecosystem Services Valuation and Wealth Accounting, stating that "the goal is to introduce the practice of ecosystem valuation into national accounts at scale so that better management of natural environments becomes 'business as usual'" (World Bank Press Release No:2011/155/SDN). This partnership is explicitly built upon on the final report of the United Nations Environment Programme "The Economics of Ecosystems and Biodiversity" (TEEB, 2011), and Chapter 6 of its "Ecological and Economic Foundations" section perhaps constitutes the most up-to-date discussion of social discounting as it relates to biodiversity and ecosystem services.

Relatedly, the System of Environmental-Economic Accounts (SEEA) is "the statistical framework that provides internationally agreed concepts, definitions, classifications, accounting rules and standard tables for producing internationally comparable statistics on the environment and its relationship with the economy. The SEEA framework follows a similar accounting structure as the System of National Accounts (SNA) and uses concepts, definitions and classifications consistent with the SNA in order to facilitate the integration of environmental and economic statistics". ${ }^{[5]}$ At the time of writing this is currently under revision (SEEA, 2011) but Annex A5.2 of the current draft version considers in detail the appropriate choice of social discount rate for use within such a framework.

Within this branch of economics, the objective of evaluating projects is to establish whether they contribute to social welfare measured in terms of utility. This is usually thought of as being a concave function of consumption of a single consumption good $c_{t}, u\left(c_{t}\right)$. Social welfare, $W$, aggregates utility over time by taking its present value: 


$$
W=u\left(c_{0}\right)+\frac{1}{(1+\rho)} u\left(c_{1}\right)+\frac{1}{(1+\rho)^{2}} u\left(c_{2}\right)+\ldots .+\frac{1}{(1+\rho)^{T}} u\left(c_{T}\right)
$$

Parameter $\rho>0$ is the 'utility discount rate' or 'pure rate of time preference' and measures how the price of utility evolves over time.

The economic approach to discounting described here is firmly rooted in the Utilitarian tradition which is consequentialist in nature. The 'goodness' in any action or policy is thereby measured in terms of the final outcomes. There is no stock placed in the process by which outcomes are arrived at and procedural ethics are ignored. It is, therefore, not without its problems. As colourfully articulated by Beckerman and Hepburn (2007), the throwing of Christians to the lions in ancient Rome may well have resulted in a positive appraisal under this type of cost-benefit analysis. Such anomalies have steered many towards alternative ethical frameworks which emphasise procedures and elements of duty that have been applied to other questions of moral ethics. Deontological approaches recognise that future generations have rights; for example, the right to a stable climate or biodiverse ecosystems. Others emphasise the present generation's duty towards future generations to not impinge upon their well-being, a perspective not completely removed from the idea of sustainable development. In defense of consequentialism, and the part it has to play in decision making, Dasgupta (2007) reminds us that it would be unwise to adhere doggedly to some particular procedural ethical stance without at the same time knowing the consequences of this position. Ultimately such tricky decisions must reflect what Rawls described as a 'reflective equilibrium', considering both the deontological and the consequentialist approaches to social ethics (Dasgupta, 2007).

Within the utility discounting approach captured in equation (2), future environmental and biodiversity costs and benefits are expressed in terms of changes in the consumption pattern, measured in monetary terms, over time. This is consistent with the monetisation of externalities within an FCA framework. Again, the focus of this paper is not in addressing the ethical, methodological or practical difficulties associated with this task. Instead we turn to the three other central elements that determine $W$. The first is the degree of concavity of the utility function, which reflects the fact that an extra unit of benefit contributes less to utility when consumption is high than when it is low. The more curved the utility function, the stronger the incentive to smooth consumption. In a standard 'power' utility function the curvature is reflected 
through the parameter $\eta$. Second, the growth rate in consumption, $g$, is of relevance. Since the curvature of the utility function reflects a desire to transfer wealth from periods of high consumption to those of low consumption, the more we expect the economy to grow, the less we will be willing to defer benefits into the future. Therefore, if we expect the world to get richer $(g>0)$, increases in both $\eta$ and $g$ will reduce the amount we will be willing to sacrifice today for benefits gained by subsequent generations. Finally, the parameter $\rho$ reflects the social 'impatience' of waiting for future utility gains. Again, increases in $\rho$ lead to a greater preference for current over future benefits.

In a growing economy, this framework implies that consumption at future time $t$ has a lower price associated with it than consumption today. Given the discount rate measures the rate of decline of this price, it must reflect these three elements. It is easy to show, and is extremely heavily documented in the economics literature, that when the objective is to maximise $W$, the discount rate, or social rate of time preference (SRTP), $\delta$, is given by:

$$
\delta=\rho+\eta g
$$

The economists' rationale for discounting future consumption within this normative framework is conceptually different from that of the positivist school of environmental accounting and, as we will discuss below, has been extremely influential in determining discounting policy in most OECD countries. However, the SRTP is not necessarily completely divorced from the standard environmental accounting approach. When all markets are competitive and devoid of frictions and distortions then $\delta$ can be replaced by $r$ in equation (3), which then becomes known as the Ramsey equation. Any project that increases the NPV of private profit will also increase social profit, hence it does not matter which framework is used to determine the discount rate to employ for socially valuable projects. When the markets are distorted by taxes on profit or consumption (e.g., income tax), this relationship breaks down. Various corrections exist in this case reflecting whether the project displaces consumption, private investment or a combination of the two (Lind, 1982).

Despite the powerful arguments in favour of the normative approach, economists remain split on intergenerational discounting (Arrow et al., 1996). Where streams of consumption are to be evaluated, the positive school will calibrate the parameters of the SRTP in order to be descriptive of market interest rates as we see them today. It is fair to say that the environmental 
accountant's approach to discounting is firmly rooted within this approach that implicitly views private profitability as being equal to social profitability. The normative school, by contrast, takes a prescriptive approach to the selection of the pure rate of time preference, $\rho$, and the curvature of the utility function, $\eta$, for use within equation (3).

The parameter $\rho$ represents the rate at which the weight placed on future generations' wellbeing by the present generation declines with the time horizon which, at the level of the individual, is akin to impatience. At the level of the planner, the parameter reflects an ethical judgement about the value of future well-being today which lies at the heart of CSR. With $\rho>0$, distant future generations' well-being counts for next-to-nothing in present value terms, no matter the magnitude of the cash flow being evaluated. While this phenomenon is true of discounting in general, a long tradition of Utilitarian economists argue that when applied to wellbeing/utility all generations should be treated equally. Luminaries of economics, including Ramsey, Pigou, Harrod, and Solow, have made this point forcefully. For instance, Ramsey famously described positive discounting of utility as 'ethically indefensible'. Harrod described it as "the conquest of reason by passion". For these reasons the Stern Review on the economics of climate change also took this view when evaluating climate change investments (Stern, 2007).

Of course, these are simply statements of belief rather than fact, and other prominent economists have taken a different stance. For instance, Kenneth Arrow has argued from the basis of 'agent relative ethics' that positive discounting of future utilities is perfectly ethical (Arrow, 1999). After all, it seems unlikely that we are ethically obliged to weigh future generations' well-being in a million years time in the same way as our own well-being today. So there are several potentially equally valid beliefs on the issue, and no clear recipe for agreement (Beckerman and Hepburn, 2007). There are ethically dubious outcomes whatever one decides about pure time preference. On the one hand, it has been shown that the incomes of future generations will be driven to almost zero by an optimising Utilitarian planner that is dependent on non-renewable resources. On the other hand, in a similar context, zero pure time preference can prescribe crippling levels of saving and investment for the current generation. So, careful thought is required on this issue for fear of 'tyrannising' the present or future generations (Dasgupta, 2005; Dasgupta and Heal, 1979).

The parameter $\eta$ has also been the source of ethical discussion. This parameter measures the 
curvature of the utility function and reflects the desire to smooth income from periods of high to low consumption. As a consequence, it captures at least three different economic effects. First, it reflects individuals' motives for smoothing consumption across time. This lies behind such fundamental economic concepts as the Permanent Income Hypothesis. Second, it captures any individual's desire to ensure that their consumption is not too volatile at any given point in time: a characteristic commonly known as risk aversion. Finally, it presents a social motive for re-distributing wealth from the richest to the poorest and to reduce social inequality. Within the normative approach to social discounting it is the first of these interpretations, the concern about the distribution of well-being and consumption over time, that is of primary concern and drives the choice of $\eta$.

\subsection{Influence on policy}

The aftermath of the Stern Review offers a salutary tale in regard to the sensitivity of intergenerational investment decisions to whether a positive or normative approach is taken to discounting. Stern took the normative view that all future well-beings should be given the same weight as the present. In the end Stern chose $\rho=0.1 \%$ to reflect the risk of societal collapse; after all, it seems reasonable to place less weight on future societies if we believe that they may not exist due to some catastrophe or other. He then selected $\eta=1$ and a central case growth estimate $g=1.4 \%$, making the SRTP $1.41 \%$. Nordhaus (2007), on the other hand took a positive approach to discounting and calibrated the parameters of the SRTP so that they matched the observed average real return to equities of around 5-6\%. On the basis of studies of observed consumption smoothing, he chose $\eta=2$. With growth at $1.5 \%$, the implicit value of $\rho=2-3 \%$. Now each approach leads to radically different policy recommendations for climate change. One measure of how each party weighs future benefits and costs differently can be found in estimates of the social cost of carbon (SCC), which is the present value of carbon damages from a ton of carbon emitted today $(£ / \mathrm{tC})$. The Stern Review estimated this at around $£ 300 / \mathrm{tC}$, while for Nordhaus the estimate was $£ 13 / \mathrm{tC}$ with the difference arising purely from the choice of descriptive against prescriptive discounting. As Nordhaus (2007, p.686) notes "The Review's unambiguous conclusions about the need for extreme immediate action will not survive the substitution of assumptions that are consistent with today's marketplace real interest rates and savings rates". As a consequence, the sensitivity of optimal environmental policy decisions to the stance taken on discounting has been at the forefront of the economic debate 
that has followed from Stern (2007); see, for example, Weitzman (2007a) and Stern (2008).

The ethical approach that Stern (2007) took has also had clear impacts on other areas of economic accounting. HM Treasury (2006, Annex 6) parameterises the Ramsey equation on similar lines and, in supplementary guidance (Lowe, 2008), directly contrasts its recommendations against those of Stern (2007). TEEB (2011, Chapter 6) concludes that a normative ethical stance is probably the most suitable in relation to biodiversity and that setting $\delta=0$ is appropriate.

Against this, both SEEA and the US Environmental Protection Agency are leaning towards the positive school. SEEA (2011, pp.282-3) states "Consequently the relevant rate should be descriptive ... because judgements are required regarding societal preferences, it is not recommended that prescriptive approaches to the determination of discount rates be used for the purposes of official statistics". Similarly the USEPA (2010, p.6-23) states that "Calculate the NPV using the consumption rate of interest ...As of the date of this publication, current estimates of the consumption rate of interest, based on recent returns to Government-backed securities, are close to $3 \% "$.

This debate around the Stern Review highlights an issue that will be central to our discussions below. "It seems generally to be the case that those rates determined on a more prescriptive basis are lower than rates determined on a descriptive basis but this is not always the case" (SEEA, 2011, p.281). This means that environmental accountants, should they base their valuations on IAS 19 and IAS 37, are likely to derive lower present values for biodiversity conservation initiatives compared to environmental economists purely from the stance that they take on discounting. As we will see in the next section, there is a second effect that amplifies this result.

\section{Declining discount rates}

Environmental economists have a second rationale for discounting long-term cash flows at a low cost of capital. This is based on the theoretical and empirical literature that asserts that the discount rate should decline with the time horizon. In subsection 4.3 we emphasise the importance that this literature has had on economic policy, but the lack of impact it has made in the field of environmental accounting. First, though, we justify the use of declining schedules of discount rates, where perhaps the most famous motivation can be found in the work of 
Weitzman (1998). His argument began with the uncontentious statement that the average rate of interest, a contender for the social discount rate, is extremely uncertain in the long run. In particular, being determined by technological change, resource constraints, population growth and other economic fundamentals, it is unlikely that average future interest rates will revert to what they were in the past. This long-run uncertainty underpins a declining discount rate. A simple example describes how.

Imagine a planner who must make a decision about a project which pays off $£ B_{t}$ at time $t$, but who is unsure about what is the 'correct' discount rate with which to discount the future. Suppose that the planner believes there are two possible and equally likely scenarios. In scenario 1 the (continuously compounded) discount rate is $1 \%$ and in scenario 2 the discount rate is $5 \%: r_{1}=1 \%$ and $r_{2}=5 \%$. Once uncertainty is resolved the discount rate remains constant forever. In scenario 1 the present value of $B_{t}$ would be $B_{t} e^{-0.01 t}$. In scenario 2 the present value would be $B_{t} e^{-0.05 t}$.

Weitzman's essential insight was that when the discount rate is uncertain, it is appropriate for the planner to evaluate the Expected Net Present Value (ENPV) of the project rather than calculating the net present value using the expected discount rate of $3 \%$. The ENPV in this example is calculated as follows:

$$
B_{t} E\left[e^{-r_{t} t}\right]=\frac{1}{2} B_{t}\left[e^{-0.01 t}+e^{-0.05 t}\right]
$$

This amounts to calculating the expected discount factor rather than using the expected discount rate. Yet estimating the expected discount factor is equivalent to discounting using the certainty equivalent discount rate, $r_{t}^{C E}$, which is defined as the certain rate that would give the same ENPV: $B_{t} e^{-r_{t}^{C E} t}=B_{t} E\left[e^{-r_{t} t}\right]$. Weitzman (1998) showed that $r_{t}^{C E}$ declines from its mean (in this case $3 \%$ ) at $t=0$ to the lowest possible value of the discount rate as the time horizon extends to infinity (in this case 1\%). Table 1 provides a numerical illustration. Column 1 shows the two possible future scenarios: $1 \%$ or $5 \%$. Rows 2 and 3 show the discount factor that would be associated with each scenario for time horizons of 1, 25, 100, 200 and 400 years. Row 4 presents the average discount factor across the two scenarios assuming they are equally likely to happen. Row 5 calculates the certainty equivalent discount rate for each time horizon. This 
illustrates the decline in $r_{t}^{C E}$ towards the lowest possible value of the discount rate of $1 \%$.

\section{[Insert Table 1 around here]}

This occurs because "from today's perspective, the only relevant limiting scenario is the one with the lowest interest rate, all of the other states at that far distant time, by comparison, are relatively much less important now because their present value has been reduced by the power of compound discounting at a higher rate" (Weitzman, 1998, p 205).

The numerical example is extremely simple but captures the essence of the argument. Naturally the result generalises to accommodate many possible future realisations of the discount rate and to different conceptions of uncertainty. ${ }^{[6]}$ The question then is how to operationalise the theory and characterise the future possible states and the probabilities that they will be realised.

\subsection{Declining discount rates in the normative framework}

To parameterise this model Weitzman (2001) undertook a survey in which he asked over 2000 PhD economists, and a smaller 'blue ribbon' subsample of 50 which included a handful of Nobel prize winners, for their preferred 'rate of interest' for discounting climate change damages. He then showed that the appropriate certainty-equivalent discount rate that resulted from the survey has a convenient closed form solution. The resulting value of $r_{t}^{C E}$ depends on the sample mean and variance of the reponses and the time horizon considered. Specifically, he showed that the decline of $r_{t}^{C E}$ with the time horizon is much quicker the greater the variance of the survey responses. This can be thought of as a measure of disagreement; the more expert opinion conflicts, the more rapid the decline in the term structure. The experts that Weitzman consulted gave a wide range of answers, ranging from $-3 \%$ to $+27 \%$, and this led to a sharply declining schedule of discount rates; see Figure 1.

\section{[Insert Figure 1 around here]}

More recently, Jouini et al. (2010) disentangled the uncertainty in the different responses to Weitzman's survey into the components of the SRTP: $\rho, \eta$ and $g$. They showed that if experts 
have varying beliefs about $\rho$ and $g$, then the appropriate certainty equivalent discount rate declines similarly but from a higher starting point. Jouini and Napp (2010) then parameterise their approach using Weitzman's data and the resulting schedule can be seen in Figure 1 (J\&N). By comparison, Weitzman's schedule falls to $2 \%$ after 200 years, whereas J\&N's schedule falls to $2.3 \%$, having started from around $5 \%$.

\subsection{Declining discount rates in the positivist framework}

The use of declining discount rates is not restricted only to those who take a normative stance to intergenerational discounting. Most notably, Newell and Pizer (2003) econometrically model the very long-term history of Government bond returns. Based on this stochastic process, they are able to determine a term structure of discount rates. Adjustments have subsequently been made to this schedule, either by changing the econometric approach (Groom et al., 2007) or the choice of data (Gollier et al., 2008).

This approach again leads to a sharply declining term structure. For example, under the Newell and Pizer (2003) parameterisation, the discount rate falls from a short-rate of $4 \%$ to $1.1 \%$ after 200 years. For Groom et al. (2007) the fall is from $4 \%$ to $1.8 \%$. Therefore, although these papers are derived in a very different paradigm from those of Weitzman (2001) and Jouini and Napp (2010), the implications for valuation are similar.

Freeman and Groom (2012) take an entirely different approach to calculating declining discount rates in a descriptive environment. They argue that many respondents to Weitzman's 2001 survey might reasonably have interpreted the question in a purely positive way. In this case, the question would be most naturally interpreted as asking for a forecast of average future real interest rates over a long horizon. Each response, $r_{i}$, can then be modelled as the 'true' discount rate, $r_{t}$, and a forecast error, $e_{i}$, with variance $\sigma_{e}^{2}$. If the planner believes that each expert is unbiased in his or her forecast, and experts are independent, then by the central limit theorem, the probability distribution that the planner can derive for the 'true' discount rate is $r_{t} \sim N\left(\bar{r}_{i}, \sigma_{e}^{2} / n\right)$, where $n$ is the number of respondents and $\bar{r}_{l}$ is the average taken across the different responses. Because Weitzman ran such a large survey, this effectively removes all uncertainty in $r_{t}$ and therefore the uncertainty that drives the declining schedule virtually disappears. As a consequence, and in notable contrast to Weitzman (2001), the resultant term 
structure is effectively flat.

Of course the assumption of over 2000 totally independent academic opinions is not realistic, and therefore Freeman and Groom (2012) extend their argument to the case of correlated forecast errors. When correlation between expert opinions is high, Freeman and Groom (2012) find that the term structure of discount rates does decline, but still more slowly than the schedules derived in other studies. For example, in their exponentially correlated case with a correlation coefficient of 0.99 , which corresponds to the same information content as approximately 10 independent experts, the discount rate declines from $4.37 \%$ at year one to $3.60 \%$ at 200 years.

In addition to the normative and positivist approaches based on the expected net present value condition, there are other justifications for declining schedules of discount rates which, for reasons of conciseness, we do not include in this paper; see, for example, Weitzman (2007b) and Gollier (2008). The principle of discounting long-term cash flows at a lower rate of return than their short-term equivalent counterparts is therefore widely accepted by environmental economists.

\subsection{The impact of declining discount rates on policy}

This declining discount rate literature has had an important impact on economic policy. For example, HM Treasury (2006) recommends a short term discount rate of $3.5 \%$, falling to $2.6 \%$ at 200 years. French government policy is for the discount rate to decline from $4 \%$ in the shortterm to $2.3 \%$ after 200 years (Lebègue, 2005). In addition, SEEA and the USEPA, both of whom can be broadly categorised in the positivist camp, and therefore closest to environmental accountants in their beliefs about how costs of capital should be estimated, explicitly recognise the problems of using market interest rates in the long-term. For example:

"A general concern on the use of market based discount rates is that they tend to be relatively higher rates which in turn tend to provide relatively low values in absolute terms beyond normal planning timeframes, say 30 years. Thus for long lived and potentially everlasting resources, the use of relatively lower rates will tend to recognise values for these resources into the future to a greater extent. Independent of any implied societal preferences, lower discount rates may therefore better reflect the likely values of these resources. Also, especially for environmental resources, the recognition of values over a longer time period may assist in understanding the problem that while the benefits received from the environment tend to be received 
immediately, the costs to the environment may only be evidenced much later. The use of declining discount rates may be a way to deal with these issues." (SEEA, 2011, p.282)

Despite this widespread recognition of the advantages of using low discount rates in the long term, to our knowledge there has been no consideration of such matters within FCA. As a consequence, environmental accountants are likely to estimate lower present values than environmental economists on biodiversity liabilities. This may again lead managers to reject environmentally friendly projects that are in the greater societal good.

In our local and global forestry case studies in Section 5, we evaluate the long-term values of biodiversity using ten different term structures of discount rates. The first is at a flat discount rate of $4 \%$. We choose this value for a number of reasons. Most importantly, it is the short-term rate given in both Newell and Pizer (2003) and Groom et al. (2007), which take a market interest rate based approach. In addition, the French government uses a short-term rate of $4 \%$, with the UK Treasury recommending a slightly lower value of $3.5 \%$. Finally, $4 \%$ is the average response of Weitzman's 2001 survey data.

The next three schedules are based on policy recommendations. We use HM Treasury (2006) Green Book guidance and that of the French government. For the UK, the rationale for the recommended schedule of DDRs is not specific to the normative or positive schools in the sense that the motivating literature references Newell and Pizer (2003) as well as Weitzman $(1998,2001)$. In the case of the French government, the approach can be thought of as normative and stemming from the model of parameter uncertainty discussed in Gollier (2008). Both schedules decline at slower rates than many academic schedules propose. We also use a flat rate of $1.4 \%$, which is close to the rate employed in the Stern Review. We then present two academic schedules based within a normative paradigm, Weitzman (2001) and Jouini and Napp (2010), before turning to four positivist term structures with declining schedules; Newell and Pizer (2003), Groom et al. (2007) and two from Freeman and Groom (2012) which correspond to low and high correlation between expert forecasts ("Many experts" and "Few experts", which have exponential correlation coefficients of 0.5 and 0.99 respectively). In Figure 1, we present eight of these term structures; Stern (2007) and Freeman and Groom (2012, "Many experts") are excluded as these are both either perfectly, or very nearly, flat.

\section{Forest biodiversity and ecosystem services}


In this section we present two examples of the differences between normative and positive and declining and non-declining discount rates for the evaluation of biodiversity- and ecosystemsensitive projects. Both examples come from forestry. The first is a local example of a forest enterprise in the UK considering whether to operate on long rotations of 120 years or on short rotations of 22 years. The species and management systems of long rotation forests also provides biodiversity values and ecosystem services for which monetary values have been estimated in the UK. The trade-off is typical of the kind of issue faced by a company; short-term gain versus long-term private losses, with biodiversity and ecosystem services provided as a public good and hence external to the narrow aim of maximising shareholder wealth.

The second example is a global example of the impact over 300 years of marginal changes in global forest cover. This example deploys the GUMBO model which was designed with the express intention of providing detailed estimates of the values of global ecosystem services.

\subsection{Forestry and biodiversity: Long versus short rotations}

Two possible management systems for forestry are compared. The short rotation is of 22 years and relates to the planting of pine. The long rotation model is of 120 years and reflects the cultivation of broad-leaved species such as oak. The cash flows associated with each rotation period are taken from Hepburn and Koundouri (2007) who in turn developed their example in consultation with the Forestry Commission. We extend this analysis by incorporating biodiversity values into the long rotation model and then comparing the present values of this approach to the case where the short rotation model is undertaken repeatedly.

The non-monetary biodiversity value of broad-leaved forests has been estimated using a variety of economic methdologies which use hypothetical or surrogate markets to impute values for the environment where no direct market exists. Stated preference methods, such as Contingent Valuation (CVM) or Choice Experiments (CE), elicit values for biodiversity from individuals by presenting hypothetical market scenarios in which monetary trade-offs are considered. With CVM, individuals are asked for their willingness to pay (WTP) for marginal changes in the level of biodiversity conservation, such as the number of species or area of habitat conserved. CE methods typically present more detailed policy. For example, respondents may be asked to choose between two policies which differ in attributes such as the number of species conserved, 
the site at which the species are conserved, the cost of the conservation policy and the mode of implementation. Both CVM and CE elicit monetary estimates of the marginal value of biodiversity.

On occasion, surrogate markets, such as housing or transport, can be used to indirectly estimate the value of non-marketed environmental goods. Typical examples include the Travel Cost and Hedonic Valuation methods. The former derives values for environmental goods from the costs of travel to sites for eco-tourism. The Hedonic method uses variation in house prices, for instance, to establish the marginal value of environmental amenities such as the proximity to parks and forests.

Experience with stated and revealed preference methods for valuing environmental goods is long and detailed and the methods themselves have improved considerably in their acceptability and robustness over the past few decades. Biodiversity valuation in the context of forests has frequently been the focus for these methods. For instance, Hanley et al. (2002) undertook a study to estimate the willingness to pay for the increase in biodiversity arising from a restructuring of remote forest activities away from single species (pine) towards native broadleaved varieties. Using CVM they found that such structural changes were worth between 61 and 84 pence per household per year. This contrasts with estimates by Garrod and Willis (1997), who also used CVM, of 35 pence per year per household for structural changes which emphasised the generation of shelterbelts rather than recreating native forests, and 100 pence per household per year for the preservation of ancient native forests.

Our case study analyses the present value of short versus long rotation forestry on a single forest plot. For the purposes of this study, we follow the more up-to-date study by Willis et al. (2003) and assume that the additional biodiversity value of the change from short-rotation to long-rotation is worth approximately 50p per household per year. These values were elicited using a stated preference CVM approach. Given this value was estimated in relation to the 96000ha of the native broad-leaved forest in the UK, and assuming that the value is representative of $25 \mathrm{~m}$ households in the UK, this gives us an approximate estimated figure for biodiversity values of $£ 120$ per hectare per year for long-rotation forests over and above the short-rotation. Table 2 shows the cash flows assumed for each forest rotation model.

[Insert Table 2 around here] 
5.2. Global Unified Meta-model of the Biosphere (GUMBO): A simulation of global forest ecosystem values

We next consider a global example of the impact of discounting choices on estimating ecosystem values. The GUMBO model that forms the foundation for this case study was designed with the express purpose of providing a comprehensive valuation of global ecosystem services (Boumans et al., 2002). We undertake a simulation on the GUMBO model which produces a schedule of marginal damages over a 300 year horizon from a marginal change in global forest cover.

GUMBO was developed in order to provide simulations of the interactions between economics and ecology by modelling them as an integrated dynamic system. Importantly, GUMBO was the first to model the complex and dynamic feedbacks between technology, production, welfare, and ecosystem goods and services. Different 'modules' model carbon, water and nutrient fluxes within 11 different ecosystems and five different 'spheres': the atmosphere (including atmospheric carbon and global temperature), lithosphere (soil, rocks etc.), hydrosphere (water, carbon and genetic nutrients in water bodies), biosphere (e.g., photosynthesis, respiration, nitrogen fixing) and lastly, economic and social consequences are modelled in an 'anthroposphere'. In the last, population change, well-being and production are modelled and can be influenced by different policy regimes and assumptions about the future concerning technological change, quantity of oil and other reserves, and so on. The parameters of the model have been calibrated to reproduce historical data on ecosystems, such as land coverage and composition of the atmosphere. The model is a synthesis of several existing dynamic global models. It contains 234 state variables, 930 variables in total and 1715 parameters. ${ }^{[7]}$

Importantly, GUMBO contains specific assumptions concerning sustainability and substitutability. The model embodies the principle of 'strong sustainability' which limits the substitutability of natural and physical capital and limits the extent to which economic growth can continue as critical natural resources and ecosystem services are depleted. GUMBO also contains several scenarios which vary the stringency of some of these assumptions and the policies implemented. In short GUMBO provides a perspective on the role of ecosystem services in generating long-run well-being which embodies some of the complex constraints such as irreversibility, non-linearity and threshold effects that typify ecosystems (Boumans et al., 
2002).

The GUMBO model was originally used to estimate the total value of ecosystem services within the earth system. For the purposes of our investigation into the impact of the choice of discount rate we undertake an alternate experiment. The theories of discounting we have discussed are only strictly valid in the context of marginal changes in consumption which leave growth relatively unaffected. The robustness of the theory to non-marginal changes has been investigated by Dietz and Hepburn (2010) and Gollier (2008). The implications are that even with perturbations of the magnitude envisaged by the Stern Review ( $5 \%$ of GDP), the marginal analysis provides a largely accurate approximation. The definition of non-marginal changes appears to be in the order of $10 \%$ of GDP. Therefore, rather than focussing on total ecosystem values we simulate instead an incremental change. This also reflects the fact that, in most policy contexts, it is the marginal values that are of interest, while this approach circumvents some, though by no means all, of the criticisms levelled at the Costanza et al. (1997) study.

We simulate the 'marginal' loss in ecosystem service values arising from a once and for all $0.01 \%$ increase in the rate of global deforestation. Several important aspects of forest ecosystem values are valued by the GUMBO model relating to seven different ecosystem services: climate regulation, gas regulation, waste assimilation, soil maintenance, disturbance/resilience, nutrient function and cultural values. Climate regulation chiefly concerns temperature and precipitation. Gas regulation concerns the chemical composition of the atmosphere, waste assimilation refers to the recovery and breaking down of nutrients. Soil maintenance concerns the processes that form soils, and nutrient function refers to the acquisition of nutrients in the global system, such as plant uptake of nitrogen. Cultural values refer to recreational activities such as eco-tourism and sport fishing as well as other activities like worship and aesthetic appreciation.

The simulation is run for 300 years and two scenarios are chosen for comparative purposes. These scenarios contain different assumptions about the way the future pans out with regard to, amongst other things, technological change and the response of ecosystems to expansion in the anthroposphere. The two scenarios that we use are pre-structured examples within the GUMBO model that we apply without alteration, and are illustratively referred to as the 'Mad Max' and the 'Big Government' scenarios. 
The Mad Max scenario is so called for its potentially apocalyptic outcomes, in the view of Boumens et al. (2002). It assumes 'technologically optimistic' policies are pursued involving high consumption and investment in built capital and a future in which very little technological change takes place and hence the beliefs driving the policies turn out to be false. The idea behind this policy is that it results in bad outcomes in the future for technological optimists in terms of resource conversion and depletion, and hence loss of ecosystem services.

The Big Government scenario assumes the opposite: 'technological skepticism' which fosters lower consumption and a shift in investment towards human and social capital. The skepticism turns out to be misplaced and technological change exceeds expectations. The difference between the state in which technology and environmental outcomes turn out to be poor and the state in which they turn out to be good are reflected in Table 3. In the Big Government scenario the effect of the application of energy on agricultural harvests and yields is higher, with parameters of 0.3 and 0.04 respectively compared to 0.2 and 0.02 in the Mad Max scenario. The policy parameters are much more prudent in the Big Government scenario compared to the Mad Max scenario. Investment is spread more equally across the three types of capital on offer (human, natural and physical) with rates of investment of 18\%, 30\% and 10\% respectively compared to $5 \%, 0 \%$ and $20 \%$ in the Mad Max scenario. The latter shows a huge reliance on physical (man-made) capital compared to natural and human capital, a strategy widely seen as unsustainable by environmental and ecological economists alike. Ultimately, the Mad Max scenario reflects a world in which poor policy meets unkind environmental resources and resilience, which leads to lower well-being in the long-run.

\section{[Insert Table 3 around here]}

These deterministic and exogenous differences in assumptions drive radical differences in the estimates of loss of ecosystem service. Feedback effects ensure that these differences arise for complicated reasons. Figure 2 shows the marginal schedule of deforestation, in millions of hectares $(\mathrm{mHa})$ per annum, from each of these scenarios. As its name implies, the Mad Max scenario leads to a significantly worse total loss in global forestry; approximately $100 \mathrm{mHa}$ against $40 \mathrm{mHa}$, representing a loss of $1 \%$ and $0.8 \%$ of global forest cover respectively. The 50 year average rates of deforestation in the base case of each scenario are 11 and $12 \mathrm{mHa}$ respectively. By way of comparison, in 2010 global deforestation was estimated at $13 \mathrm{mHa}$ (FAO, 2010). 


\section{[Insert Figure 2 around here]}

Figure 3 shows the total loss of ecosystem services in the Mad Max and Big Government scenarios expressed in terms of trillions of dollars. We have used a polynomial filter to smooth these numbers for presentation purposes but use the raw estimates when calculating present values below. It is easy to see that the losses gradually increase over time for approximately the first 100 years and oscillate somewhat thereafter. The gradual changes reflect inertia in climate regulatory systems, waste assimilation and nutrient cycles, and the oscillation reflects differences in the evolution of ecosystem values in each scenario. The GUMBO model is integrated and so deforestation has impacts on a wide variety of factors in the anthroposphere, such as population growth, via changes in ecosystem services. The total losses are composed of losses in the full range of ecosystem services provided by forests.

\section{[Insert Figure 3 around here]}

In the Big Government scenario, the skeptical policies combined with better than expected technological and ecological outcomes lead to a large attenuation of the ecosystem values after 100 or so years, before returning to a higher level. The effect in terms of ecosystem services has similar qualitative features in the Mad Max scenario, but the losses are lower in the long run. What is surprising is that, while Mad Max leads to a much greater degree of deforestation than Big Government, its total undiscounted costs over 300 years are actually smaller; $\$ 31$ th against $\$ 51$ tn. This reflects the differences in technological and policy assumptions that occur in each scenario, and hence the way in which ecosystem services are valued in each case.

Figures 4 and 5 show the disaggregation of these losses into the seven categories of ecosystem service: climate regulation, gas regulation, waste assimilation, soil maintenance, disturbance/resilience, nutrient function and cultural values. Only four lines are shown in each case, though, as waste costs are identical to soil costs and both gas and disturbance costs are identical to climate costs. Of these values, waste assimilation / soil maintenance are by far the most affected by deforestation. This is followed by gas / climate / disturbance regulation. The least affected are the cultural values and nutrient recycling.

[Insert Figures 4-5 around here] 


\section{Results}

\subsection{The local example}

Table 4 shows how the net present value of the long and short-rotation management approaches for forestry varies by discounting approach. The first thing to notice is that using the standard environmental accounting approach with a constant market interest rate of $4 \%$ favours short-rotation forests. Even if one uses the UK Treasury recommended SRTP, shortrotation forests are preferred. Using the normative approach, advocated by the Stern Review, the long-term payoffs of long-rotation forests and their associated biodiversity benefits are emphasised and their NPV is higher than the short-rotation alternative. So the outcome of the analysis depends very much on whether one takes a positive view or a normative view of discounting.

\section{[Insert Table 4 around here]}

When it comes to declining discount rates, which for such long time horizons are argued to be more appropriate, the outcome of the NPV analysis depends not just on whether one takes a normative or a positive view, but also on whether one uses historical data or expert opinion in order to describe the uncertainty in the discount rate. On the normative side, using Weitzman (2001) which, as shown by Figure 1, has a sharply declining schedule of discount rates, leads to a positive NPV for long-rotation, relatively biodiversity-rich, forests. The Jouini and Napp (2010) approach does not, since although the schedule declines rapidly with the time horizon, it starts from a higher discount rate due to heterogeneity in expert opinions about growth and the pure rate of time preference. On the positivist side, both the Newell and Pizer (2003) and Groom et al. (2007) approaches indicate that long-rotation forests are to be preferred. However, if one assumes that experts were forecasting the future, rather than providing normative opinions, as do Freeman and Groom (2012), then the discount rate schedule barely declines and the NPV analysis favours short-rotation forests.

This is a clear illustration that the evaluation of biodiversity benefits supplied by forests is strongly determined by the approach taken to discounting long time horizons. However, by using the discount rate schedules of Newell and Pizer (2003) and Groom et al. (2007), which combine accountants' natural preference for basing costs of capital on market interest rates with 
a declining schedule estimated from historic Treasury bond yields, we can see that there is strong justification for choosing biodiversity-friendly long-rotation forestry practice in preference to planting pine.

\subsection{The global example}

Tables 5 and 6 show the present value of each component of the ecosystem service under the two scenarios discussed: Mad Max and Big Government. The rows present results for different schedules of discount rates, while the columns present the valuation for different components of the total ecosystem. The final column, "Ratio", provides the Total figure for that term structure divided by the Total figure for the flat $4 \%$ discount rate case.

\section{[Insert Tables 5 and 6 around here]}

While the choice of scenario significantly affects each individual value, it has little effect on the relationship between different choices of discount rate and biodiversity valuation, which is the primary focus of interest in this paper.

The lowest valuations are given by the two schedules of Freeman and Groom (2012), which have high ("Few experts") and low ("Many experts") correlation between expert forecasts, and the $4 \%$ flat rate. This is because the short-term discount rate is around $4 \%$ in each case and the schedule either does not drop at all or declines very slowly.

Using the recommendations of the UK and French governments leads to valuations between $60 \%$ and $110 \%$ more than the $4 \%$ case respectively. Similar increases in present values compared to the flat $4 \%$ rate are obtained from the normative approach of Jouini and Napp (2010). Here the schedule declines at a similar, rapid rate to many other academic studies but starts from a higher initial value (see Figure 1).

With valuations between $130 \%$ and $300 \%$ higher than the $4 \%$ case are the academic schedules of Weitzman (2001), Newell and Pizer (2003) and Groom et al. (2007). The highest valuations of all, more than $400 \%$ higher than the $4 \%$ case, are derived with the discounting framework of the Stern Review (2007). This is unsurprising as a very low discount rate (1.4\%) is recommended at all horizons in this case. 
The results show that using a flat discount rate at long-term average real bond yields has the potential to substantially understate the true social costs of biodiversity degradation. This can be true whether one takes a positive perspective, like Newell and Pizer (2003), and Groom et al. (2007), or a normative approach, like Jounin and Napp (2010), and Weitzman (2001).

Typically, conventional flat rate discounting using a market-based cost of capital will underestimate the social costs of biodiversity degradation. This is in keeping with earlier findings concerning the Stern Review and the conclusions of SEEA (2011). It should, though, be noted that the environmental accounting approach will, under certain circumstances, result in higher present values than the economic accounting approach. For example, at the time of writing, the term structure of index-linked UK Treasury bonds is negative at all horizons. A discount rate derived from this curve would be lower than any of the term structures considered above. This, though, is an unusual situation and it is not obvious that a manager should use the current yield on a 30-year bond to value a 300 year cash flow in preference to the longer historical analysis of interest rates contained in, for example, Newell and Pizer (2003).

\section{Conclusion}

In this paper we have provided guidance to Full Cost Accountants concerning the appropriate choice of long-term discount rate. We have then applied this guidance to both a local and a global biodiversity-sensitive project concerning forestry.

Financial accounting conventions for valuing long-term liabilities, such as nuclear decomissioning expenses and pension fund obligations, prescribe the use of current market based discount rates, which are commonly interpreted to be the yields on AA-rated corporate bonds. Our central observation is that these conventions are not appropriate for biodiversityand environmentally-sensitive costs and benefits. There are three main reasons for drawing this conclusion. First, biodiversity-sensitive projects often have implications that stretch for many centuries, yet markets do not trade corporate bonds of this maturity. Applying a 30-year bond yield to a 300-year cash flow is clearly problematic. Second, financial market yields are influenced by the richest in society today, yet ecological decisions should reflect the attitudes of all, both today and in future generations. Third, investor behaviour in financial markets is driven by a narrow desire to make money, which may not reflect the same individuals' attitudes when considering the wider society and the environment. 
To address these problems we have turned to the extensive literature within environmental economics on the long-term social rate of time preference (SRTP). Two central observations emerge. First, there is a deep divide between economists who think that the SRTP should be based on ethical judgements concerning intergenerational justice and those who, like financial accountants, prefer instead to look at financial markets. This debate has been ongoing for decades and there is unlikely to be a swift resolution. Fortunately, though, economists on both sides of this divide have now reached something of a concensus. There is broad agreement that lower costs of capital should be used to discount long-term certainty-equivalent cash flows than their short-term equivalent counterparts.

Given this, our recommendation is that Full Cost Accountants follow the proposed guidance of the US Environmental Protection Agency, which is currently considering its position on this issue. ${ }^{[8]}$ This points toward the use of declining discount rates based on historical interest rate data, such as those recommended by Newell and Pizer (2003) and Groom et al. (2007). We believe that this approach may well also be best for company managers since it balances the accounting convention of basing costs of capital on observed market interest rates with a recognition of the benefits of declining discount rates. If starting at a short-term real rate of $4 \%$, this results in a recommendation of a real discount rate of $3.00 \%$ to be applied at 50 years, so that the present value of $£ 1$ in 50 years equals $\exp (-0.03 * 50)=0.22313$. The real discount rate then declines further to $2.25 \%$ at 100 years, $1.50 \%$ at 200 years and $1.15 \%$ at 300 years.

This recommendation will help socially responsible companies capture, in financial terms, the full social benefits of retaining a diverse biosphere. As we have shown, this leads to a robust justification for opting for the planting of long-term oak forests in preference to pine; a decision that would not generally be reached under current financial accounting conventions. 


\section{Endnotes}

[1] There are surprisingly few analyses of this type in the literature. Prior to TEEB (2011), which we discuss in Section 3, important exceptions include Hepburn and Koundouri (2007), who looked at the implications of using declining discount rates on forest policy. Hepburn et al. (2010) analyse behavioural issues associated with the use of DDRs on fishery management, while in a similar context Ludvig et al. (2005) analyse specific issues concerning discount rates, again in a natural resource modelling context. These papers are not concerned specifically with ecosystem values and the importance of discounting for the far-distant time horizons associated with biodiversity conservation, which is our focus of attention here.

[2] Appealing to environmental economics to improve Full Cost Environmental Accounting methods is not, in itself, a novel concept. For example Herbohn (2005) conducts an environmental accounting experiment which is "based on a damage cost reporting system in which net profit is adjusted for positive and negative estimates of environmental externalities using valuation techniques from environmental economics." (p.519). Where this study differs methodologically from previous work is that our focus is on the discount rate component of the net present value calculation rather than estimates of the relevant monetised environmental costs and benefits.

[3] This excludes any real option values that might arise from undertaking the project.

[4] We explicitly exclude discussions of risk premia from our analysis by assuming that the environmental benefits are 'zero-beta'. As we will see, there are many challenges to face even in a risk-free world. Alternatively, we can view $\pi_{t}$ as being a certainty-equivalent monetary value. This is consistent with the view of Zeckhauser and Viscusi $(2008$, p. 96) that "economists generally agree that whoever is the decision maker, the discount rate should not be adjusted for risk. The preferred approach, roughly speaking, is to address risk by converting monetary payoffs to certainty equivalents and then do the discounting."

[5] http://unstats.un.org/unsd/envaccounting/seea.asp (accessed 21 January 2013).

[6] The theoretical basis for the ENPV approach can be found in Gollier and Weitzman (2010) and Traeger (2012), among others. Other extensions of this essential principle can be found in Arrow et al. (2012).

[7] Boumans et al. (2002) provides more information on the workings of the GUMBO model. Such is the scope of the model that it would be impossible to present a comprehensive equation-by-equation description with such limited space. The STELLA model, upon which the GUMBO model runs, is available as freeware at: http://www.iseesystems.com/softwares/Player/iseePlayer.aspx. The GUMBO model can be downloaded from: http://ecoinformatics.uvm.edu/projects/the-gumbo-model.html (both accessed 21 January 2013).

[8] http://rff.org/Events/Pages/Intergenerational-Discounting-Workshop.aspx (accessed 21 January 2013). 


\section{References}

Antheaume, N. (2007), "Full cost accounting: Adam Smith meets Rachel Carson?", in Unerman, J., O'Dwyer, B., and Bebbington, J. (Eds.), Sustainability Accounting and Accountability, Routledge, London.

Arrow, K.J. (1999), "Discounting, Morality, and Gaming", in Portney, P.R. and Weyant, J.P. (Eds.), Discounting and Intergenerational Equity, Resources for the Future, Washington, DC.

Arrow, K.J., Cline, W.R., Maler, K.-G., Munasinghe, M., Squitieri, R., and Stiglitz, J.E. (1996), "Intertemporal equity, discounting and economic efficiency", in Bruce, J.P., Lee, H. and Haites, E.F. (Eds.), Climate Change 1995 - Economic and Social Dimensions of Climate Change, Cambridge University Press, Cambridge.

Arrow, K.J., Cropper, M.L., Gollier, C., Groom, B., Heal, G.M., Newell, R.G., Nordhaus, W.D., Pindyck, R.S., Pizer, W.A., Portney, P.R., Sterner, T., Tol, R.S.J. and Weitzman, M.L. (2012), "How should benefits and costs be discounted in an intergenerational context? The views of an expert panel", Resources for the Future Discussion Paper, RFF DP 12-53.

Bebbington, J. and Frame, B. (Undated), "Moving from SD reporting to evaluation: the sustainability assessment model", working paper, St Andrews University.

Beckerman W. and Hepburn C. (2007), "Ethics of the discount rate in the Stern Review on the Economics of Climate Change". World Economics, Vol. 8 No. 1, pp. 187-210.

Boumans R., Constanza R., Farley J., Wilson, M., Portela R., Rotmans, J., Villa, F. and Grasso M. (2002), "Modeling the dynamics of the intergrated earth systemand the value of global ecosystem services using the GUMBO model". Ecological Economics, Vol. 41 No. 3, pp. 529-560.

Boyce, G. (2000), "Public discourse and decision making: Exploring possibilities for financial, social and environmental accounting", Accounting Auditing \& Accountability Journal, Vol. 13 No. 1 , pp. 27-64. 
Brennan, N.M. and Solomon, J. (2008), “Corporate governance, accountability and mechanisms of accountability: an overview", Accounting, Auditing \& Accountability Journal, Vol. 21 No. 7, pp.885-906.

Costanza, R., d'Arge, R., de Groot, R., Farber, S., Grasso, M., Hannon, B., Limburg, K., Naeem, S., O'Neill, R.V., Paruelo, J., Raskin, R.G., Sutton, P. and van den Belt, M. (1997), "The value of the world's ecosystem services and natural capital", Nature Vol. 387 No. 6630, pp. 253-260.

Dasgupta, P. (2005), "Three conceptions of intergenerational justice”, in Lillehammer, H. and Mellor, D.H. (Eds), Ramsey’s Legacy,... Clarendon Press, Oxford.

Dasgupta, P. (2007), “Commentary: The Stern Review's economics of climate change”, National Institute Economic Review, Vol. 199 No. 1, pp. 4-7.

Dasgupta, P. and Heal G.M. (1979), Economic Theory and Exhaustible Resources, Cambridge University Press, Cambridge.

Davies, J. (2009), "The application of full cost accounting in a higher education context development of a methodological approach". Paper presented at the $1^{\text {st }}$ International Conference on Sustainable Management of Public and Not for Profit Organisations, University of Bologna, July 2009.

Dietz, S. and Hepburn, C.J. (2010), “On non-marginal cost-benefit analysis”, working paper, Centre for Climate Change Economics and Policy, No. 20.

Elkington, J. (2003), "Enter the triple bottom line”, in Henriques, A. and Richardson, J. (Eds.), The Triple Bottom Line, Does It All Add Up? Assessing the Sustainability of Business and CSR, Earthscan, London.

FAO (2010), Global Forest Assessment Survey, Food and Agriculture Organisation of the United Nations, Rome.

Freeman, M.C. and Groom, B. (2012), "Positively gamma discounting”, working paper, School 
of Business and Economics, Loughborough University.

Garrod, G.D. and Willis, K.G. (1997), "The non-use benefits of enhancing forest biodiversity: A contingent ranking study", Ecological Economics, Vol. 21 No. 1, pp. 45-61.

Gollier, C. (2008), "Discounting with fat-tailed economic growth", Journal of Risk and Uncertainty, Vol. 37 No. 2, pp. 171-186.

Gollier, C. (2012), "The debate on discounting: Reconciling positivists and ethicists", working paper, Toulouse School of Economics.

Gollier, C., Koundouri, P. and Pantelidis, T. (2008), "Declining discount rates: Economic justifications and implications for long-run policy", Economic Policy, Vol. 23 No. 56, pp. 757795.

Gollier, C. and Weitzman, M. (2010), "How should the distant future be discounted when discount rates are uncertain?", Economics Letters, Vol. 107 No.3, pp. 350-353.

Grabsch, C., Jones, J. and Solomon, J. (2012), "Accounting for biodiversity in crisis: A European Perspective", working Paper, Kings College, London.

Groom, B., Koundouri, P., Panopoulou, E. and Pantelidis, T. (2007), "Discounting the distant future: How much does model selection affect the certainty equivalent rate?", Journal of Applied Econometrics, Vol. 22 No. 3, pp. 641-656.

Guthrie, J. and Parker, L.D. (2011), "Reflections and projections: 25 years of interdisciplinary perspectives on accounting, auditing and accountability research", Accounting, Auditing \& Accountability Journal, Vol. 25 No. 1, pp. 6-26.

Hanley, N., Willis, K., Powe, N. and Anderson, M. (2002), Valuing the Benefits of Biodiversity in Forests, Social \& Environmental Benefits of Forestry Phase 2, Report to the Forestry Commission, Edinburgh. Centre for Research in Environmental Appraisal and Management, University of Newcastle upon Tyne. 
Hepburn C.J., Duncan S. and Papachristodoulou, A. (2010), "Behavioural economics, hyperbolic discounting and environmental policy", Environmental and Resource Economics, Vol. 46 No. 2, pp.189-206.

Hepburn, C.J. and Koundouri, P. (2007), "Recent advances in discounting: Implications for forest economics", Journal of Forest Economics, Vol. 13 No. 2, pp. 169-189.

Herborn, K. (2005), "A full cost environmental accounting experiment", Accounting, Organizations and Society, Vol. 30 No. 6, pp. 519-536.

HM Treasury (2006), The Green Book: Appraisal and evaluation in central government, HM Treasury, London.

Houdet, J., Pavageau, C., Trommetter, M. and Weber, J. (2009), "Accounting for changes in biodiversity and ecosystem services from a business perspective: Preliminary guidelines towards a Biodiversity Accountability Framework", working paper, Departement d'Economie, Ecole Polytechnique, No. 2009-44.

Jones, M.J. (2003), “Accounting for biodiversity: Operationalising environmental accounting”, Accounting, Auditing \& Accountability Journal, Vol. 16 No. 5, pp. 762-789.

Jones, M.J., (2010), “Accounting for the environment: Towards a theoretical perspective for environmental accounting and reporting", Accounting Forum, Vol. 34 No. 2, pp. 123-138.

Jouini, E. and Napp, C. (2010). “Aggregation of Discount Rates: An Equilibrium Approach”, working paper; Université Paris-Dauphine.

Jouini, E., Marin, J-M.and Napp, C. (2010), "Discounting and Divergence of Opinion”, Journal of Economic Theory, Vol. 145 No. 2, pp. 830-859.

Justus, J., Colyvan, M., Regan, H. and Maguire, L. (2009), "Buying into conservation: intrinsic versus instrumental value", Trends in Ecology \& Evolution, Vol. 24 No. 4, pp. 187-191.

Lebègue, D. (2005), "Révision du taux d'actualisation des investissements publics", 
Commissariat général du Plan.

Lind, R. (1982), "A primer on the major issues relating to the discount rate for evaluating national energy options", in Lind, R. (Ed.), Discounting for Time and Risk in Energy Policy, Resources for the Future, Washington, pp. 21-114.

Lowe, J. (2008), "Intergenerational wealth transfers and social discounting: Supplementary Green Book guidance", discussion paper, HM Treasury.

Ludvig, D., Brock, W.A, and Carpenter, S.R. (2005), "Uncertainty in discount models and environmental accounting", Ecology and Society, Vol. 10 No. 2, pp. 13-25.

McCauley, D.J. (2006). "Selling out on nature", Nature, Vol. 443 No. 7107, pp. 27-28.

Meinard, Y. and Grill, P. (2011), "The economic valuation of biodiversity as an abstract good", Ecological Economics, Vol. 70 No. 10, pp. 1707-1714.

Newell, R.G. and Pizer, W.A. (2003), "Discounting the distant future: How much do uncertain rates increase valuations?", Journal of Environmental Economics and Management, Vol. 46 No. 1, pp. 52-71.

Nordhaus, W.D. (2007), "A review of the Stern Review on the economics of climate change", Journal of Economic Literature, Vol. 45 No. 3, pp. 686-702.

Richardson, J., and Bent, D. (2003), The Sigma Guidelines - Sustainability Accounting Guide. http://www.projectsigma.co.uk/Toolkit/SIGMASustainabilityAccounting.pdf $\quad$ (accessed: 21 January 2013).

SEEA (2011), "Revision of the system of environmental - economic accounts", United Nations Committee of Experts on Environmental Economic Accounting (UNCEEA), Statistics Division / Department of Economic and Social Affairs, United Nations, Draft Version for Second Round of Global Consultation, October 2011.

Sen, A. (1982), "Approaches for the choice of discount rates for social benefit-cost analyses", in 
Lind, R.C. (Ed.), Discounting for time and risk in energy policy, Resources for the Future, Washington DC.

Stern, N.H., (2007), The Economics of Climate Change, Cambridge University Press, Cambridge.

Stern, N.H. (2008), "The economics of climate change", American Economic Review: Papers and Proceedings, Vol. 98 No. 2, pp. 1-37.

Sterner, T. and Persson, U.M. (2008), "An even Sterner Review: Introducing relative prices into the discounting debate", Review of Environmental Economics and Policy, Vol. 2 No. 1, pp. 61-76.

Taylor, S. (2008), "How should investors value nuclear liabilities?", working paper, Judge Business School, Cambridge University, No. 04/2008.

TEEB (2011), The Economics of ecosystems and biodiversity in national and international policy making, ten Brink, P. (Ed.), UNEP/Earthscan.

Toman, M. (1998), "Why not to calculate the value of the world's ecosystem services and natural capital?", Ecological Economics, Vol. 25 No. 1, pp. 57-60.

Traeger, C.P. (2012), "What's the rate: Disentangling the Weitzman and Gollier effect", working paper, Department of Agricultural and Resource Economics, University of California, Berkeley, CUDARE Working Paper 1121.

Weitzman, M.L. (1998), "Why the far-distant future should be discounted at its lowest possible rate", Journal of Environmental Economics and Management, Vol. 36 No. 3, pp. 201-208.

Weitzman, M.L. (2001), "Gamma discounting", American Economic Review, Vol. 91 No. 1, pp. 260-271.

Weitzman, M.L. (2007a), "A review of the Stern Review on the economics of climate change", Journal of Economic Literature, Vol. 45 No. 3, pp. 703-724. 
Weitzman, M.L. (2007b), "Subjective expectations and asset-return puzzles", American Economic Review, Vol. 97 No. 4, pp. 1102-1130.

Willis, K. G., Garrod, G., Scarpa, R., Powe, N., Lovett, A., Bateman, I.J., Hanley, N. and Macmillan, D.C. (2003), The Social and Environmental Benefits of Forests in Great Britain, Report to Forestry Commission, Edinburgh.

USEPA (2010), Guidelines for Preparing Economic Analyses, National Center for Environmental Economics, Office of Policy, US Environmental Protection Agency.

Zeckhauser, R.J. and Viscusi, W.K. (2008), "Discounting dilemmas: Editors' introduction", Journal of Risk and Uncertainty, Vol. 37 No. 2, pp. 95-106. 
Table 1: Declining Discount Rates

\begin{tabular}{cccccc}
\hline Discount Rate Scenarios & $\mathbf{t}=\mathbf{1}$ & $\mathbf{t}=\mathbf{2 5}$ & $\mathbf{t}=\mathbf{1 0 0}$ & $\mathbf{t}=\mathbf{2 0 0}$ & $\mathbf{t = 4 0 0}$ \\
\hline $\mathbf{1 \%}$ & 0.99 & 0.78 & 0.37 & 0.14 & 0.02 \\
$\mathbf{5 \%}$ & 0.95 & 0.29 & 0.01 & 0.00 & 0.00 \\
\hline Average Discount Factor & 0.97 & 0.53 & 0.19 & 0.07 & 0.01 \\
\hline Certainty Equivalent Discount Rate & $2.98 \%$ & $2.52 \%$ & $1.67 \%$ & $1.35 \%$ & $1.17 \%$ \\
\hline
\end{tabular}

This table presents a simple illustrative example showing that the certainty equivalent discount rate, when calculated from the expected net present value criterion, falls towards the lowest possible value as the time horizon approaches infinity.

Table 2: Cash Flows and Biodiversity Values: Long versus Short Rotations

\begin{tabular}{|c|c|c|c|c|}
\hline \multirow[b]{2}{*}{ Activity } & \multicolumn{2}{|c|}{$\begin{array}{c}\text { Short Rotation } \\
\text { (22 Years) }\end{array}$} & \multicolumn{2}{|c|}{$\begin{array}{c}\text { Long Rotation } \\
\text { (120 Years) }\end{array}$} \\
\hline & Years & Cash Flow & Years & Cash Flou \\
\hline Site preparation & 0 & -50 & 0 & -100 \\
\hline Planting and tree protection & 0 & -200 & 0 & -800 \\
\hline Road construction & 0,12 & -75 & 0,12 & -75 \\
\hline Annual operating costs & $0-22$ & -20 & $0-120$ & -20 \\
\hline Weed control & 1 & -50 & 1 & -100 \\
\hline Pre-commercial thinning & $4,7,10,13$ & -15 & 5,20 & -200 \\
\hline Thinning 1 & 8 & 200 & 60 & 4000 \\
\hline Thinning & 12 & 350 & 80 & 8000 \\
\hline Thinning 3 & 16 & 500 & 100 & 10000 \\
\hline Clearfall & 22 & 4000 & 120 & 12000 \\
\hline Biodiversity values & $0-22$ & 0 & $20-120$ & 120 \\
\hline
\end{tabular}

This table presents the cash flows for use in our local case study of forestry biodiversity benefits in the UK. 
Table 3: Parameter Values for Simulation Scenarios

\begin{tabular}{lrr}
\hline & Big Government & Mad Max \\
\hline Agriculture (crops) & & \\
\hline Effect of Energy on Plant Harvest & 0.3 & 0.2 \\
Effect of Energy on Yields & 0.04 & 0.02 \\
& & \\
\hline Savings Rates & & 0.05 \\
Human capital & 0.18 & 0 \\
Natural capital & 0.3 & 0.2 \\
Physical capital & 0.1 & \\
\hline Resources & & 600 \\
\hline Accessible Oil & 800 & 3000 \\
Assimilation Capacity & 7000 & \\
\hline
\end{tabular}

This table presents key parameter choices for the two simulations that we run within GUMBO.

Table 4: Present Value of Forestry and Biodiversity: Long versus Short Rotations

\begin{tabular}{lccr}
\hline & $\begin{array}{c}\text { Long Rotation } \\
\text { (120 Year) }\end{array}$ & $\begin{array}{c}\text { Short Rotation } \\
\text { (22 Years) }\end{array}$ & Difference \\
\hline Discounting Approach & Panel A: Flat Term Structure & -1754.3 \\
\hline Flat 4\% & 898.6 & 2652.9 & Panel B: Policy Recommendations \\
\hline & 2467.9 & 3541.6 & -1073.7 \\
UK Treasury "Green Book" & 3464.8 & 3681.1 & -216.3 \\
French Government & 12118.0 & 8738.0 & $\mathbf{3 3 8 0 . 0}$ \\
Stern (2007, Flat 1.4\%) & Panel C: Normative Declining Discount Rate Schedule \\
& 4255.3 & 4217.0 & $\mathbf{3 8 . 3}$ \\
Weitzman (2001) & 2510.0 & 3150.0 & -640.0 \\
Jouini and Napp (2010) & Panel D: Positive Declining Discount Rate Schedule \\
& 4076.8 & 3688.0 & $\mathbf{3 8 8 . 8}$ \\
Newell and Pizer (2003) & 5962.4 & 5302.5 & $\mathbf{6 5 9 . 8}$ \\
Groom et al. (2007) & 887.7 & 2642.6 & -1754.9 \\
Freeman and Groom (2012) Many Experts & 775.1 & 2464.3 & -1689.2 \\
Freeman and Groom (2012) Few Experts & \multicolumn{3}{c}{. } \\
\hline
\end{tabular}

This table presents the present value of long rotation and short rotation forestry practices in the UK under ten different schedules of discount rates. 


\begin{tabular}{|c|c|c|c|c|c|c|c|c|c|}
\hline Discounting Approach & Gas & Climate & Disturbance & Soil & Nutrient & Waste & Cultural & Total & Ratio \\
\hline & \multicolumn{9}{|c|}{ Panel A: Flat Term Structure } \\
\hline Flat $4 \%$ & 0.149 & 0.149 & 0.149 & 0.273 & 0.020 & 0.273 & 0.071 & 1.084 & 1.00 \\
\hline & \multicolumn{9}{|c|}{ Panel B: Policy recommendations } \\
\hline UK Treasury "Green Book" & 0.242 & 0.242 & 0.242 & 0.457 & 0.034 & 0.457 & 0.112 & 1.788 & 1.65 \\
\hline French Government & 0.300 & 0.300 & 0.300 & 0.572 & 0.045 & 0.572 & 0.135 & 2.228 & 2.05 \\
\hline \multirow{2}{*}{ Stern (2007, Flat 1.4\%) } & 0.831 & 15.174 & 1.355 & 13.512 & 1.356 & 13.502 & 1.361 & 13.474 & 12.43 \\
\hline & \multicolumn{9}{|c|}{ Panel C: Normative declining discount rate schedule } \\
\hline Weitzman (2001) & 0.361 & 0.361 & 0.361 & 0.696 & 0.054 & 0.696 & 0.161 & 2.698 & 2.49 \\
\hline \multirow[t]{2}{*}{ Jouini and Napp (2010) } & 0.246 & 0.246 & 0.246 & 0.467 & 0.036 & 0.467 & 0.111 & 1.822 & 1.68 \\
\hline & \multicolumn{9}{|c|}{ Panel D: Positivist declining discount rate schedule } \\
\hline Newell and Pizer (2003) & 0.499 & 0.499 & 0.499 & 0.977 & 0.079 & 0.977 & 0.211 & 3.734 & 3.44 \\
\hline $\begin{array}{l}\text { Groom et al. (2007) } \\
\text { Freeman and Groom (2012) Manv }\end{array}$ & 0.455 & 0.455 & 0.455 & 0.880 & 0.069 & 0.880 & 0.202 & 3.404 & 3.14 \\
\hline Experts & 0.149 & 0.149 & 0.149 & 0.272 & 0.020 & 0.272 & 0.071 & 1.080 & 1.00 \\
\hline Freeman and Groom (2012) Few Experts & 0.141 & 0.141 & 0.141 & 0.258 & 0.019 & 0.258 & 0.067 & 1.024 & 0.94 \\
\hline
\end{tabular}

This table presents the present value of the loss of ecosystems services under the Mad Max scenario in trillions of dollars. Ten different schedules of discount rates are used. The "Ratio" figure gives the Total present value under each scenario divided by the Total present value under the $4 \%$ flat discount rate schedule. 
Table 6: "Big Government"

\begin{tabular}{|c|c|c|c|c|c|c|c|c|c|}
\hline Discounting Approach & Gas & Climate & Disturbance & Soil & Nutrient & Waste & Cultural & Total & Ratio \\
\hline & \multicolumn{9}{|c|}{ Panel A: Flat Term Structure } \\
\hline \multirow[t]{2}{*}{ Flat $4 \%$} & 0.230 & 0.230 & 0.230 & 0.469 & 0.046 & 0.469 & 0.078 & 1.791 & 1.00 \\
\hline & \multicolumn{9}{|c|}{ Panel B: Policy recommendations } \\
\hline UK Treasury "Green Book" & 0.369 & 0.369 & 0.369 & 0.739 & 0.074 & 0.739 & 0.128 & 2.842 & 1.59 \\
\hline French Government & 0.445 & 0.445 & 0.445 & 0.885 & 0.089 & 0.885 & 0.157 & 3.407 & 1.90 \\
\hline \multirow[t]{2}{*}{ Stern (2007, Flat 1.4\%) } & 1.221 & 1.221 & 1.221 & 2.397 & 0.244 & 2.397 & 0.435 & 9.286 & 5.19 \\
\hline & \multicolumn{9}{|c|}{ Panel C: Normative declining discount rate schedule } \\
\hline Weitzman (2001) & 0.539 & 0.539 & 0.539 & 1.072 & 0.108 & 1.072 & 0.191 & 4.130 & 2.31 \\
\hline \multirow[t]{2}{*}{ Jouini and Napp (2010) } & 0.364 & 0.364 & 0.364 & 0.730 & 0.073 & 0.730 & 0.128 & 2.804 & 1.57 \\
\hline & \multicolumn{9}{|c|}{ Panel D: Positivist declining discount rate schedule } \\
\hline Newell and Pizer (2003) & 0.843 & 0.843 & 0.843 & 1.692 & 0.167 & 1.692 & 0.315 & 6.470 & 3.61 \\
\hline $\begin{array}{l}\text { Groom et al. (2007) } \\
\text { Freeman and Groom (2012) Many }\end{array}$ & 0.669 & 0.669 & 0.669 & 1.324 & 0.134 & 1.324 & 0.237 & 5.113 & 2.86 \\
\hline Experts & 0.229 & 0.229 & 0.229 & 0.467 & 0.046 & 0.467 & 0.078 & 1.782 & 1.00 \\
\hline Freeman and Groom (2012) Few Experts & 0.214 & 0.214 & 0.214 & 0.437 & 0.043 & 0.437 & 0.073 & 1.666 & 0.93 \\
\hline
\end{tabular}

This table presents the present value of the loss of ecosystems services under the Big Government scenario in trillions of dollars.

Ten different schedules of discount rates are used. The "Ratio" figure gives the Total present value under each scenario divided by the Total present value under the $4 \%$ flat discount rate schedule. 


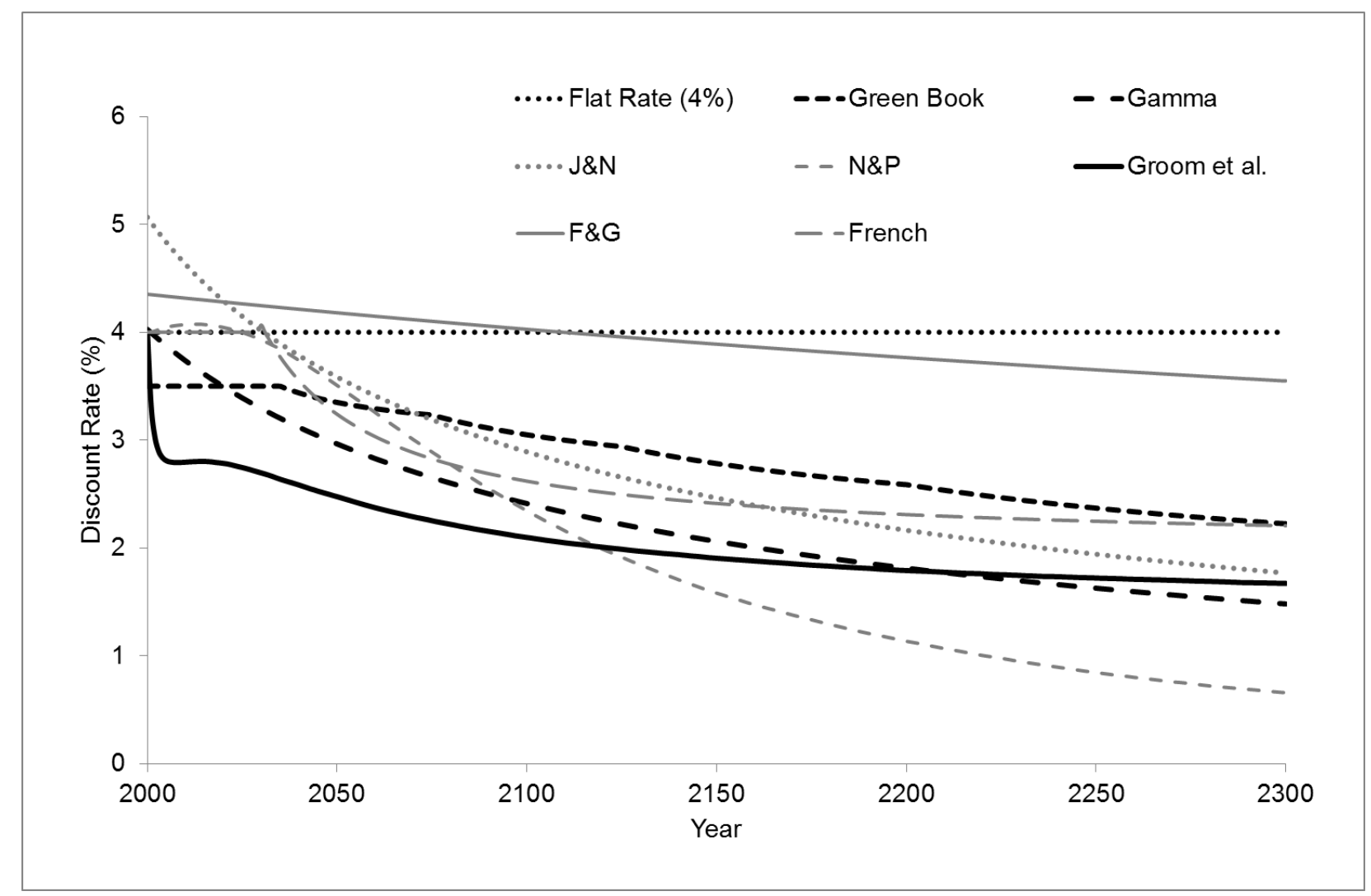

Figure 1. This graph presents the schedule of many different discount rates over a 300 year horizon. "Green Book" is the recommendation from the UK Treasury (2006), while "French" corresponds to current French Government recommendations.

"Gamma" is the gamma discounting schedule of Weitzman (2001). This, and the Jouini and Napp (2010; J\&N) schedule, are from a normative framework. The schedules of Newell \& Pizer (2003; N\&P), Groom et al. (2007) and Freeman and Groom (2012; F\&G) are in the positivist framework, with the final one refering to the case where there is high correlation between expert forecasts (correlation coefficient of 0.99). 


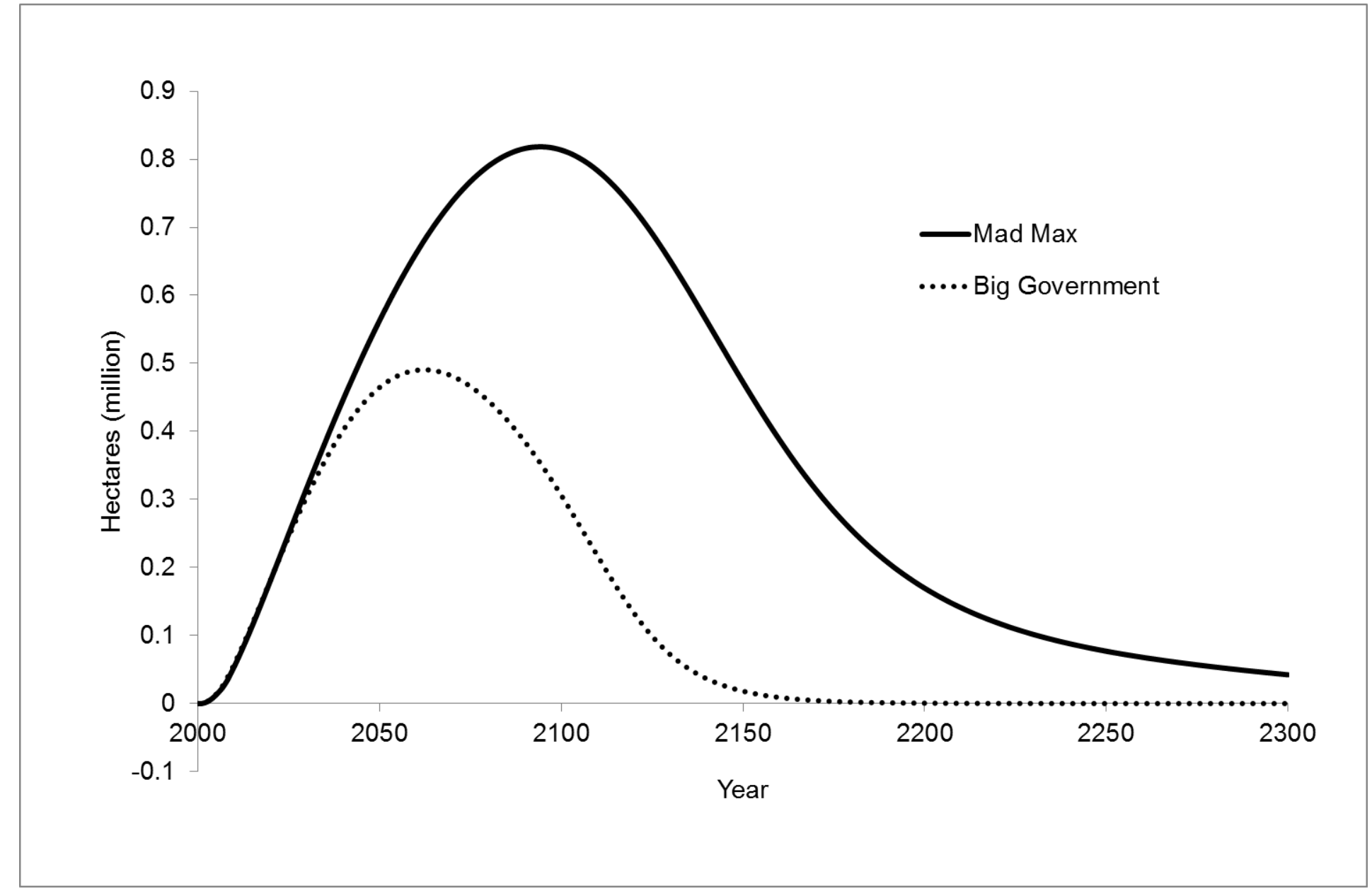

Figure 2. This figure presents the annual loss of forests under the Mad Max and Big Government scenarios in millions of hectares $(\mathrm{mHa})$ that arises from a once and for all immediate increase in global deforestation of $0.01 \%$. The total losses are approximately $100 \mathrm{mHa}$ and $40 \mathrm{mHa}$ respectively, representing $1 \%$ and $0.8 \%$ of global forest cover respectively. 


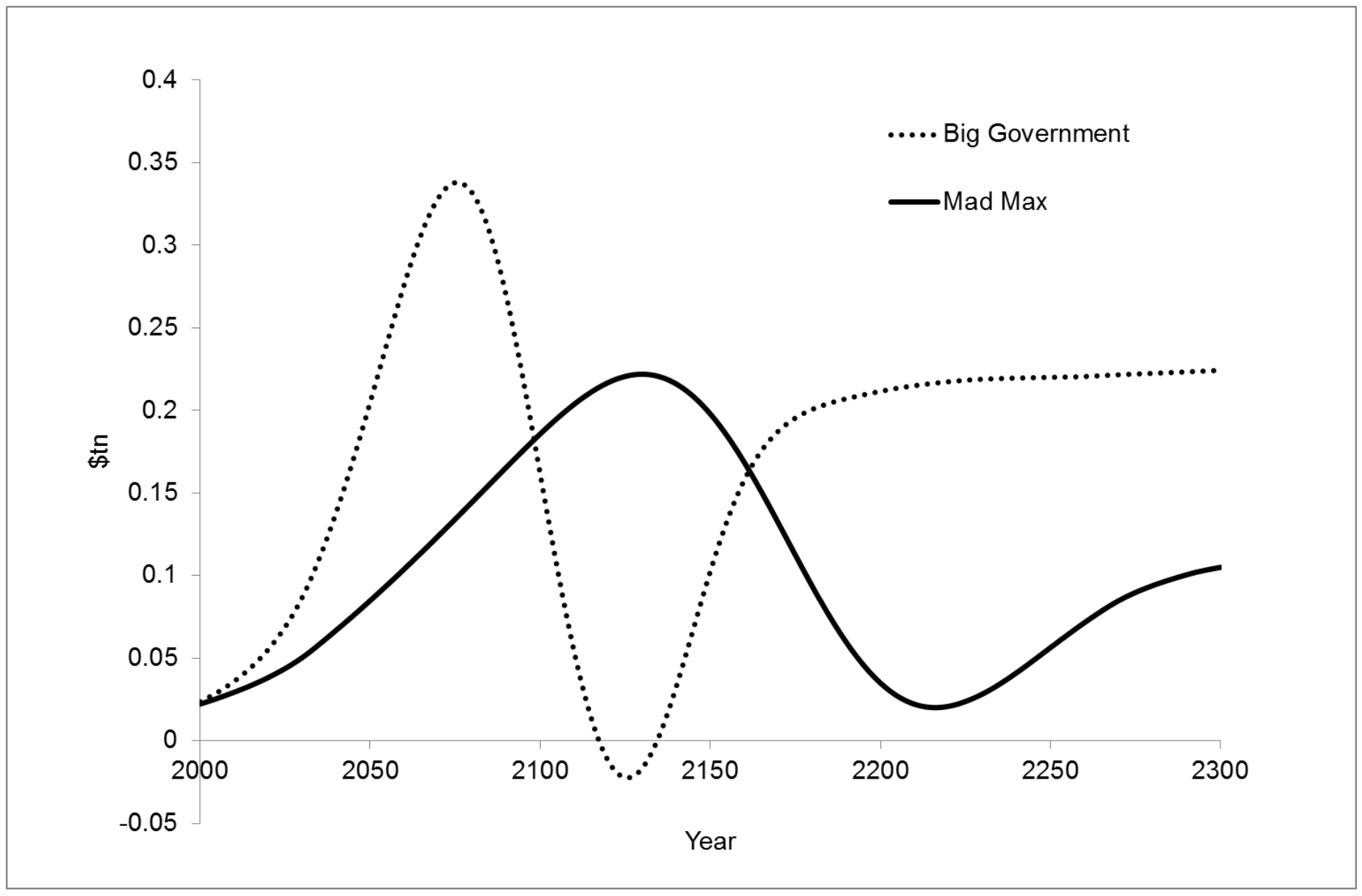

Figure 3. This figure presents the total loss of ecosystem services under the two scenarios expressed in trillions of dollars. The numbers have been polynomially smoothed in this graph for presentation purposes, but the raw data are used when calculating net present values. The total, undiscounted, costs over 300 years are \$51.3th for Big Government and \$31.3tn for Mad Max. 


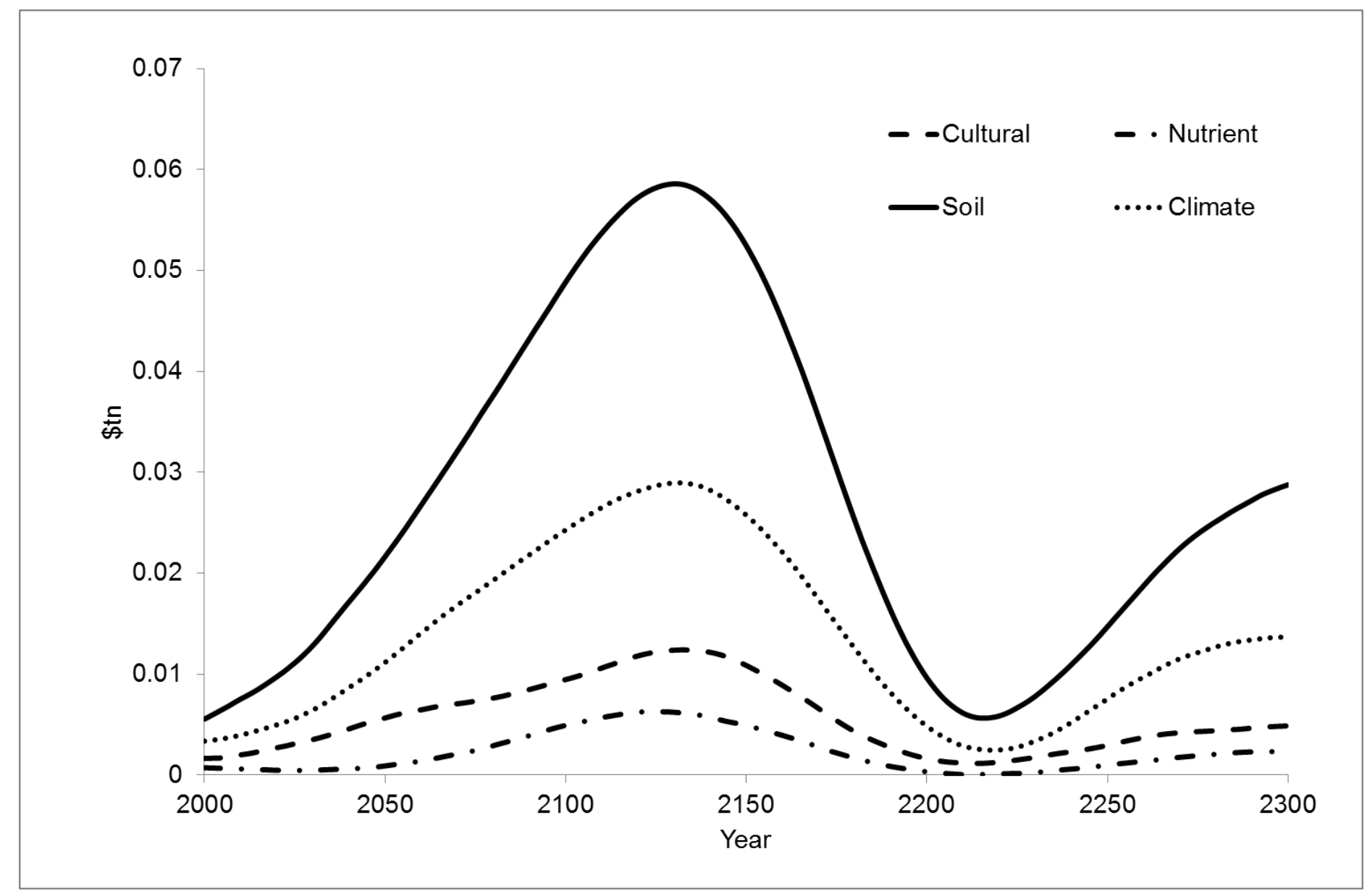

Figure 4. This figure presents the breakdown of the loss of ecoystem services by category for the Mad Max scenario. Figures are presented in \$tn after polynomial smoothing. Three other categories of costs are not shown. Waste costs are identical to Soil costs and both Gas and Disturbance costs are identical to Climate costs. 


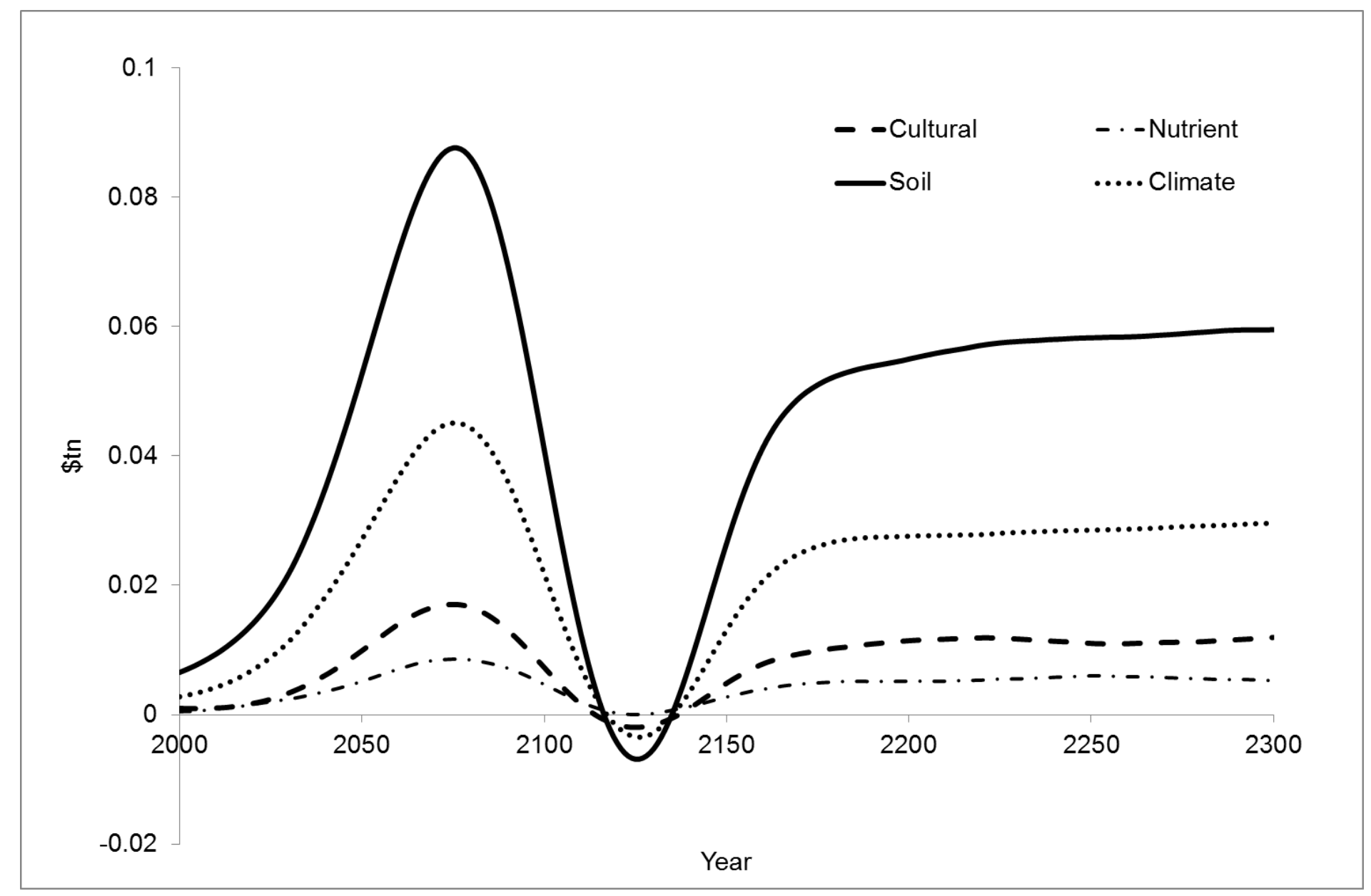

Figure 5. This figure presents the breakdown of the loss of ecoystem services by category for the Big Government scenario.

Figures are presented in \$tn after polynomial smoothing. Three other categories of costs are not shown. Waste costs are identical to Soil costs and both Gas and Disturbance costs are identical to Climate costs 